\title{
Carbon Nanotubes Disrupt Iron Homeostasis and Induce Anemia of Inflammation through Inflammatory Pathway as a Secondary Effect Distant to Their Portal-of-Entry
}

\author{
Juan Ma, Ruibin Li, Yin Liu, Guangbo Qu, Jing Liu, Wenli Guo, Haoyang Song, \\ Xinghong Li, Yajun Liu, Tian Xia, Bing Yan, and Sijin Liu*
}

\begin{abstract}
Although numerous toxicological studies have been performed on carbon nanotubes (CNTs), a few studies have investigated their secondary and indirect effects beyond the primary target tissues/organs. Here, a cascade of events are investigated: the initiating event and the subsequent key events necessary for the development of phenotypes, namely CNT-induced pro-inflammatory effects on iron homeostasis and red blood cell formation, which are linked to anemia of inflammation (AI). A panel of CNTs are prepared including pristine multiwall CNTs (P-MWCNTs), aminated MWCNTs $\left(M W C N T s-N_{2}\right)$, polyethylene glycol MWCNTs (MWCNTs-PEG), polyethyleneimine MWCNTs (MWCNTS-PEI), and carboxylated MWCNTs (MWCNTs-COOH). It has been demonstrated that all CNT materials provoke inflammatory cytokine interleukin-6 (IL-6) production and stimulate hepcidin induction, associated with disordered iron homeostasis, irrespective of exposure routes including intratracheal, intravenous, and intraperitoneal administration. Meanwhile, PEG and $\mathrm{COOH}$ modifications can ameliorate the activation of IL-6-hepcidin signaling. Long-term exposure of MWCNTs results in AI and extramedullary erythropoiesis. Thus, an adverse outcome pathway is identified: MWCNT exposure leads to inflammation, hepatic hepcidin induction, and disordered iron metabolism. Together, the combined data depict the hazardous secondary toxicity of CNTs in incurring anemia through inflammatory pathway. This study will also open a new avenue for future investigations on CNT-induced indirect and secondary adverse effects.
\end{abstract}

Dr. J. Ma, Dr. G. Qu, Dr. J. Liu, Dr. W. Guo, Dr. H. Song, Prof. X. Li,

Prof. S. Liu

State Key Laboratory of Environmental

Chemistry and Ecotoxicology

Research Center for Eco-Environmental Sciences

Chinese Academy of Sciences

Beijing 100085 , China

E-mail: sjliu@rcees.ac.cn

Prof. R. Li

School for Radiological and

Interdisciplinary Sciences (RAD-X)

Collaborative Innovation Center of Radiation

Medicine of Jiangsu Higher Education Institutions

Soochow University

Suzhou 215123, China

DOI: $10.1002 /$ smll.201603830
Dr. Y. Liu, Prof. B. Yan

School of Chemistry and Chemical Engineering

Shandong University

Jinan 250100, China

Dr. Y. Liu

Beijing Jishuitan Hospital

Peking University Health Science Center

Beijing 100035, China

Prof. T. Xia

Division of NanoMedicine

Department of Medicine

University of California

Los Angeles, CA 90095, USA 


\section{Introduction}

Owing to the novel physicochemical properties, carbon-based nanomaterials have continuously attracted great attention in biomedical and pharmaceutical applications. ${ }^{[1]}$ Among carbonaceous nanomaterials, carbon nanotubes (CNTs) with 1D structure possess many preferential features, such as light weight, chemical stability, strong nonspecific adsorption, and conversion of absorbed near-infrared light heat, ${ }^{[2]}$ which enable the development of a wide spectrum of usages including imaging, tissue regeneration, and drug or gene delivery ${ }^{[1,3-5]}$ Meanwhile, the increasing use of CNTs may cause adverse health effects through ingestion, injection, and inhalation. ${ }^{[6]}$ Previous studies have suggested that CNTs could trigger asbestos-like pathogenicity in the lung, such as pro-inflammatory responses and formation of granulomas and fibrosis, due to their fiber-like shape. ${ }^{[7-11]}$ Nevertheless, sustained growth of CNT products will be likely restrained by the lack of a pragmatic risk assessment paradigm, especially under the low-dose exposure settings, such as daily use exposure and environmental exposure.

We previously demonstrated that silver nanoparticles remarkably induced compensatory and adaptive responses that forced a switch of the energy mode from oxidative phosphorylation-based aerobic metabolism to anaerobic glycolysis for the rapid demand of energy in both cancer and noncancer cells at sublethal concentrations. ${ }^{[12]}$ By contrast, regarding CNTs, although a large number of studies have described their toxicity, these studies mainly focused on the direct toxic effects on the targeted tissues/organs, and few data demonstrated their indirect toxicity beyond primary targets (e.g., liver and lung) thus far. ${ }^{[13,14]}$ Only limited data suggested that exposure to nanosized carbon black elicited significant hepatic responses mainly through metabolic pathways in the offspring, implying that carbon black caused disorders in liver-mediated metabolism. ${ }^{[15,16]}$ Nonetheless, these findings pinpointed the significance of exploring the secondary and compensatory responses to CNTs, particularly through liver-mediated homeostasis.

Liver is the predominant organ for immunological modulation of systemic inflammation and in controlling iron homeostasis, ${ }^{[17-20]}$ e.g., the inflammation-hepatic hepcidinferroportin (FPN) axis in modulating systemic iron absorption and distribution. ${ }^{[21,22]}$ Iron is an essential biometal necessary for most forms of lives, and it plays a crucial role in diverse biological processes for iron-containing proteins, including hemoglobin (HGB) in red blood cells (RBCs), enzymes responsible for DNA replication, and repair and mitochondrial energy metabolism. ${ }^{[23,24]}$ Mammals have evolved an elegant network to maintain systemic iron homeostasis in order to balance iron absorption, trafficking, storage, and utilization under normal settings. The hepcidinFPN axis fundamentally governs the flow and distribution of iron by limiting iron absorption from the intestine and egress from macrophages. ${ }^{[25-28]}$ Dysregulation of this axis results in a variety of disorders, such as iron-deficiency anemia, anemia of inflammation (AI), or iron overload diseases.

We recently discovered another secondary adverse effect of carboxylated multiwall CNTs (MWCNTs-COOH):
MWCNTs-COOH-induced pro-inflammatory cytokines could result in synovial inflammation by undermining the priming state of synoviocytes and chondrocytes. ${ }^{[29]}$ To our knowledge, there has been no study of the potential effects on iron metabolism and $\mathrm{RBC}$ formation upon exposure to CNTs. To this end, in the current study, we aimed to examine CNT-induced toxicity from the prospective of iron homeostasis and iron utilization for erythropoiesis. Our findings collectively unearthed a new mechanism to understand the indirect effects of carbon nanotubes: disordered iron homeostasis and anemia of inflammation through inflammatory pathway. To our knowledge, this is the first study to report such a secondary toxic effect for CNTs.

\section{Results}

\subsection{Preparation and Characterization of MWCNTs}

Pristine MWCNTs (termed P-MWCNTs) were used as the starting material to prepare the following derivatives: aminated MWCNTs (MWCNTs- $\mathrm{NH}_{2}$ ), polyethylene glycol MWCNTs (MWCNTs-PEG), polyethyleneimine MWCNTs (MWCNTs-PEI), and MWCNTs-COOH. The physicochemical properties of these prepared MWCNTs were thereafter characterized. As shown in Figure 1A, transmission electron microscope (TEM) results revealed that all the materials appeared in a typical fiber-like structure. When performing this experiment, we prepared an array of samples with different concentrations. All MWCNTs showed favorable polydispersity and stability without significant agglomeration within $2 \mathrm{~d}$ in water, and modified MWCNTs revealed better polydispersity and stability than P-MWCNTs over a longer time period. P-MWCNTs, MWCNTs- $\mathrm{NH}_{2}$, and MWCNTsPEI (particularly P-MWCNTs and MWCNTs- $\mathrm{NH}_{2}$ ) tended to agglomerate and precipitate after $2 \mathrm{~d}$. In contrast, MWCNTsPEG and MWCNTs-COOH exhibited excellent stability and dispersion even after $14 \mathrm{~d}$. Serum, in fact, helped increase the dispersability of all MWCNTs including P-MWCNTs in culture medium with $10 \%$ fetal bovine serum (FBS). The zetapotential data indicated that PEG and $\mathrm{COOH}$ tubes showed strong negative charge in water, while PEI tubes exhibited strong positive charge in water (Figure 1B). Of note, MWCNTs- $\mathrm{NH}_{2}$ showed reduced negative charge, suggesting that hexane diamine could successfully neutralize the negative charge on MWCNTs-COOH. However, conjugated $\mathrm{NH}_{2}$ groups were likely not enough to reverse the negative charge from $\mathrm{COOH}$ groups. Nonetheless, all these MWCNT materials were negatively charged in cell culture medium with $10 \%$ FBS (Figure 1B), likely due to the formation of protein corona on tube surface in biological settings. ${ }^{[30,31]}$

A series of additional characterizations were performed. Thermogravimetric analysis (TGA) was carried out to characterize the surface coatings on MWCNTs. Figure 1C shows TGA curves for P-MWCNTs, MWCNTs-NH $\mathrm{N}_{2}$, MWCNTs-PEI, MWCNTs-PEG, and MWCNTs-COOH, respectively. There was no mass loss around $200{ }^{\circ} \mathrm{C}$, indicative of no contamination of organic pollutants (Figure 1C), in parallel to the results of polycyclic aromatic hydrocarbon 
(A)

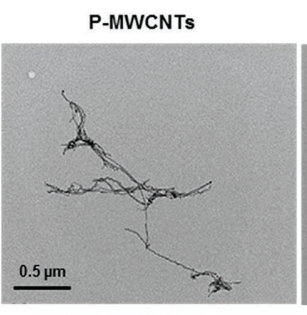

MWCNTs-NH

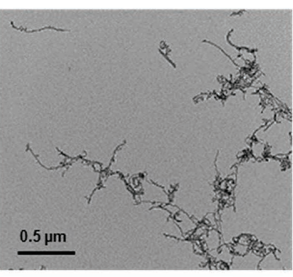

MWCNTS-PE

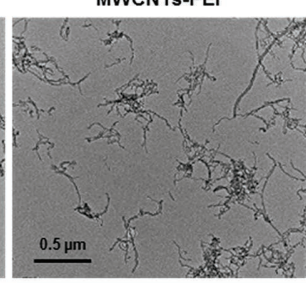

MWCNTs-PEG

MWCNTs-COOH
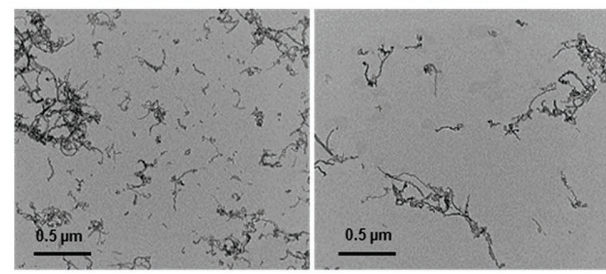

(B)

\begin{tabular}{|l|c|c|}
\hline \multirow{2}{*}{$\begin{array}{c}\text { CNT } \\
\text { samples }\end{array}$} & \multicolumn{2}{|c|}{ Zeta-potential (mV) } \\
\cline { 2 - 3 } & In $\mathrm{H}_{2} \mathrm{O}$ & $\begin{array}{c}\text { In culture } \\
\text { medium }\end{array}$ \\
\hline P-MWCNTs & $-23 \pm 1.10$ & $-8.65 \pm 0.64$ \\
\hline MWCNTs-NH & $-18 \pm 0.67$ & $-11.00 \pm 0.24$ \\
\hline MWCNTs-PEI & $17 \pm 0.67$ & $-6.82 \pm 0.14$ \\
\hline MWCNTs-PEG & $-31 \pm 0.64$ & $-6.55 \pm 0.56$ \\
\hline MWCNTs-COOH & $-36 \pm 1.23$ & $-7.87 \pm 0.31$ \\
\hline
\end{tabular}

(C)

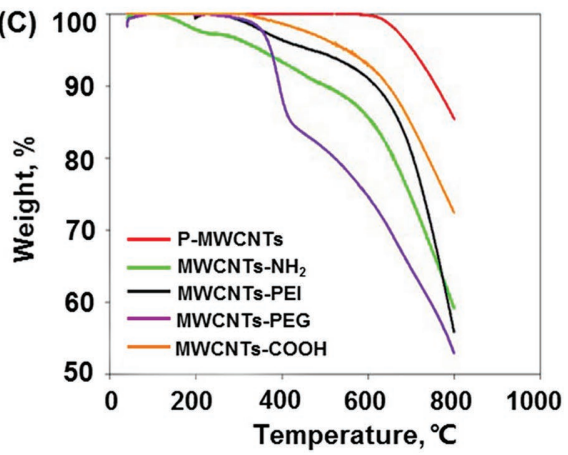

(D)

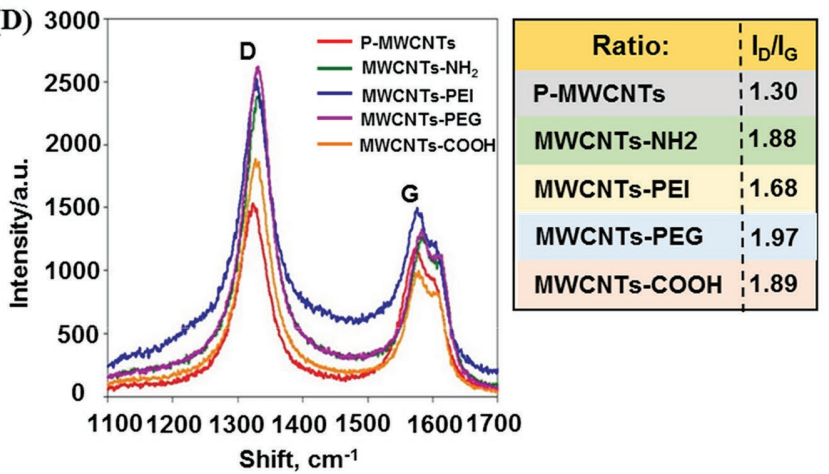

Figure 1. Physicochemical characterization of MWCNTs. A) TEM images of P-MWCNTs, MWCNTs-NH ${ }_{2}$, MWCNTs-PEI, MWCNTs-PEG, and MWCNTs$\mathrm{COOH}$. B) Quantitative analysis of zeta-potential of MWCNT samples in water and culture medium $(n=5)$. C) TGA curves of MWCNT samples. D) Raman spectrum of MWCNT samples with curve fitting of $D$ band and $G$ band. The average ratio of $I_{D} / I_{G}$ was shown in the right panel.

(PAHs) assessment, as described below. The major mass loss of MWCNTs occurred at $\approx 600{ }^{\circ} \mathrm{C}$ (Figure 1C), signifying the preparation protocol of MWCNTs- $\mathrm{NH}_{2}$, MWCNTsPEI, and MWCNTs-PEG through further modification of MWCNTs-COOH. These mass losses were accounted for by the decomposition and carbonization of $\mathrm{COOH}$, PEG, PEI, and $\mathrm{NH}_{2}$, in analogy to the previous results. ${ }^{[32]}$ Thereafter, we calculated the content of functional groups through quantifying nitrogen for MWCNT post modifications. ${ }^{[33]}$ The mass of functional groups in each MWCNT sample was similarly around $0.3-0.4 \mathrm{mmol} \mathrm{g}^{-1}$, demonstrating a similar mass of functional groups loaded on the surface of all modified MWCNTs. Based on the TGA curves (Figure 1C), the mass losses of P-MWCNTs, MWCNTs-NH ${ }_{2}$, MWCNTs-PEI,
MWCNTs-PEG, and MWCNTs-COOH were $14 \%, 40 \%$, $42 \%, 48 \%$, and $27 \%$, respectively. These results were in parallel to the theoretically estimated values, as the molecular weight of PEG is the highest among these functional groups, and P-MWCNTs possess few functional groups. Meanwhile, the little weight loss of P-MWCNTs suggested that the thermal stability of nanotubes was rather high. The Raman spectra revealed similar basal structure profiles with characteristic D peak $\left(1330 \mathrm{~cm}^{-1}\right)$ and G peak $\left(1575-1583 \mathrm{~cm}^{-1}\right)$ for all MWCNT samples (Figure 1D), consistent with published results. ${ }^{[34]}$ After calculation, a similar $I_{\mathrm{D}} / I_{\mathrm{G}}$ ratio was demonstrated for the modified MWCNTs, without statistically significant difference among them (Figure 1D, the right panel), whereas their $I_{\mathrm{D}} / I_{\mathrm{G}}$ ratio was greater than that of 
P-MWCNTs, indicating that the modification process, in fact, increased the defect sites on the MWCNT surface. ${ }^{[35,36]}$

In terms of the purity of the samples, we used highly pure P-MWCNTs as the starting materials to further synthesize MWCNTs with diverse functional groups. No metal catalytic agents were used in the synthesis processes. We carefully checked the contamination of heavy metals through inductively coupled plasma mass spectrometry (ICP-MS) after digesting the samples. Our results showed that the levels of impurities (e.g., $\mathrm{Al}, \mathrm{Ag}, \mathrm{Cd}, \mathrm{Hg}$, $\mathrm{Pb}$, and $\mathrm{Cr}$ ) were under the detection limit, thus ruling out the contamination of heavy metals. Furthermore, the levels of PAHs were determined, including 16 environmental protection agency (EPA)-PAHs (acenaphthene, acenaphthylene, fluorene, phenanthrene, anthracene, fluoranthene, pyrene, benzo (a) anthracene, chrysene, benzo (b) fluoranthene, benzo (k) fluoranthene, benzoapyrene, indeno(1,2,3cd)pyrene, dibenz (a,h)anthracene, naphthalene and benzo $(\mathrm{g}, \mathrm{h}, \mathrm{i})$ perylene). ${ }^{[37,38]}$ The concentrations of PAHs in our samples were from 29.7-43.01 ppb, less than the level in vehicle control (47.21 ppb), excluding the possible contaminations of PAHs. ${ }^{[39,40]}$ The average level of endotoxin in MWCNT samples was $0.095 \mathrm{EU} \mathrm{mL}^{-1}$, much lower than the US threshold for purified water $\left(0.25 \mathrm{EU} \mathrm{mL}^{-1}\right),{ }^{[41,42]}$ suggesting no significant endotoxin contamination in our samples.
(A)

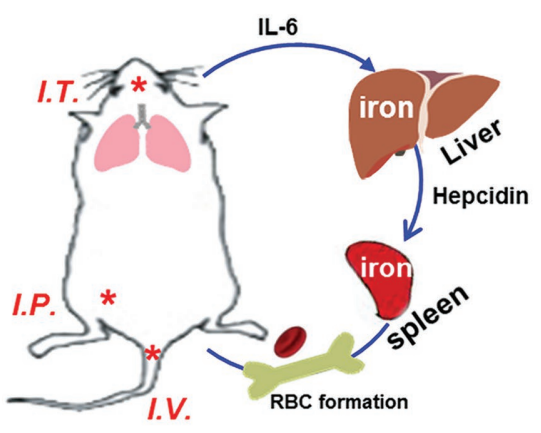

(B) In serum (I.T. 2 days)

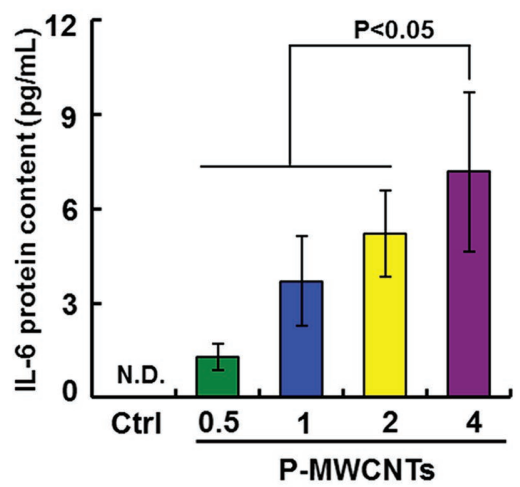

(C) In serum (I.T. 2 days)

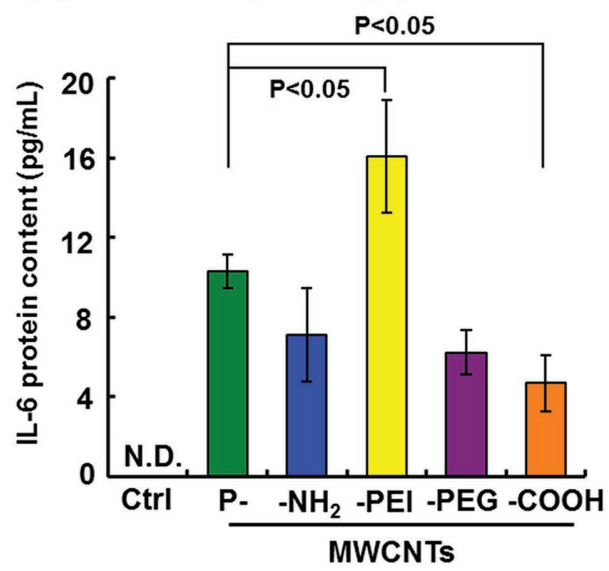

Figure 2. MWCNTs promoted the induction of IL-6 through I.T. administration. A) A schematic diagram delineating the rationale for the study of the proinflammatory effects on hepcidincentered iron homeostasis and RBC formation in mice following MWCNT exposure with different administration routes. B) Concentrations of IL- 6 in sera were measured through ELISA following I.T. administration in mice at $0.5,1,2$, or $4 \mathrm{mg} \mathrm{kg}^{-1}$ body weight P-MWCNTs for $2 \mathrm{~d}(n=6)$. C) IL-6 concentration in sera from mice upon I.T. administration at $4 \mathrm{mg} \mathrm{kg}^{-1}$ body weight of P-MWCNTs, MWCNTs-NH ${ }_{2}$, MWCNTs-PEI, MWCNTs-PEG, or MWCNTs-COOH for $2 \mathrm{~d}(n=6)$. N.D. denotes not detectable.

\subsection{Pro-inflammatory Responses to Inhalation Exposure of Diverse MWCNTs in Mice}

Carbon nanomaterials are mainly exposed to humans by inhalation and deposited to respiratory system, and then they may locate to extra pulmonary organs, such as liver. ${ }^{[14,43]} \mathrm{We}$ here systemically evaluated liver-centered iron homeostasis in mice through intratracheal (I.T.) exposure (namely I.T. administration) of various MWCNTs (Figure 2A). CNTs have been shown to induce significant toxicities to the lung. ${ }^{[8,44,45]}$ The close relevance of the predictive toxicological paradigm for toxicities to lung in humans should take into account the real-life exposure scenarios at workplaces, namely, the occupational exposure settings. As suggested in the recent studies, ${ }^{[46-48]}$ when the lung burden and the state of CNT dispersion are maintained constant, pulmonary responses to bolus exposure (e.g., oropharyngeal aspiration) are comparable to short-term inhalation exposure in rodents. However, the inhalation method involves sophisticated setup that few laboratories could perform. Thus, for lung exposure, the oropharyngeal aspiration method for bolus administration is mostly used. ${ }^{[46,49]}$ To extrapolate the bolus doses used in our animal experiments for more realistic reflection of CNT exposure in humans, we referenced the airborne levels of MWCNTs in a research facility, which reached as high as $400 \mu \mathrm{g} \mathrm{m}^{-3} \cdot{ }^{[47,48]}$ The alveolar epithelium surface area is $0.05 \mathrm{~m}^{2}$ for a mouse with a body weight of $25 \mathrm{~g}$, and it is $102 \mathrm{~m}^{2}$ for an human adult. ${ }^{[50]}$ With the calculation formula recommend by National Institute for Occupational Safety and Health (USA), ${ }^{[51]}$ it premised on that the same alveolar surface area exposure dose would generate similar toxicological effects between human and mouse; the exposure for a worker to $400 \mu \mathrm{g} \mathrm{m}^{-3}$ for $8 \mathrm{~h} \mathrm{~d}^{-1}$ over a 5 month period for 45 years during the working life time would be equivalent to $2 \mathrm{mg} \mathrm{kg}^{-1}$ for murine lung burden. ${ }^{[52]}$ Of note, the actual concentration of dust in the air during haze weather or the concentration of CNTs in working place is much higher than $400 \mu \mathrm{g} \mathrm{m}^{-3}$. [51,53] Therefore, to more realistically and accurately determine the risks of MWCNTs in promoting inflammatory responses, we screened $0.5,1,2$, and $4 \mathrm{mg} \mathrm{kg}^{-1}$ MWCNTs in mice through oropharyngeal aspiration, namely I.T. administration. 
(A)

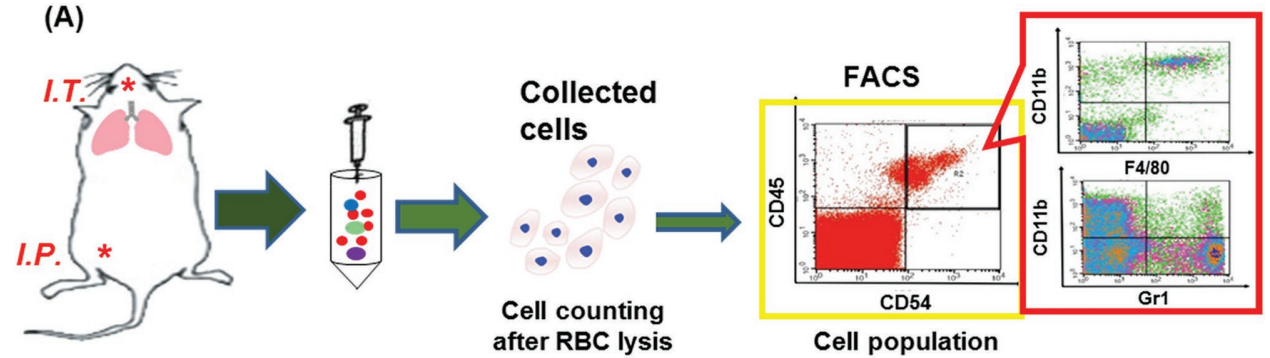

(B) In BAL (I.T. 2 days)
Macrophages

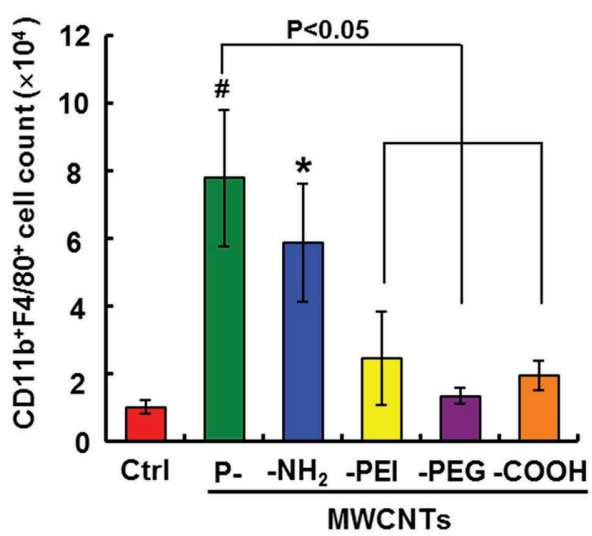

(C)

In BAL (I.T. 2 days)

Neutrophils

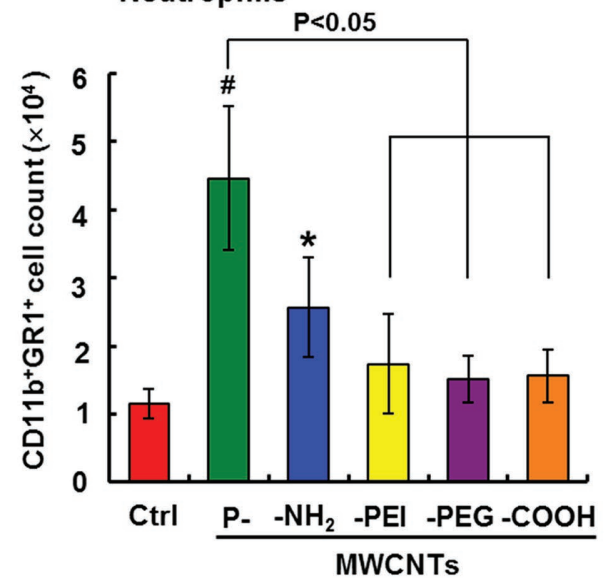

Figure 3. MWCNTs stimulated pro-inflammatory responses in lungs. A) A schematic diagram showing the flow chart for the analysis of cell sorting and subpopulation determination in BAL and in peritoneal lavages collected from mice following I.T. or I.P. administration of MWCNTs for 2 d. B) Number of $\mathrm{CD} 11 \mathrm{~b}^{+} \mathrm{F} 4 / 80^{+}$subpopulation of $\mathrm{CD} 45^{+} \mathrm{CD} 54^{+}$population. C) Number of CD $11 \mathrm{~b}^{+} \mathrm{GR} 1^{+}$subpopulation among $\mathrm{CD} 45^{+} \mathrm{CD} 54^{+}$population. There were six biological replicates per group $(n=6)$.

Since interleukin-6 (IL-6) plays an important role in the pro-inflammatory reactions and systemic inflammation, ${ }^{[54-56]}$ the serum IL-6 level was first assessed in mice following CNT administration. As shown in Figure 2B, a significant induction of inflammatory cytokine IL-6 was observed in mice upon exposure of MWCNTs at various concentrations $(P<$ $0.05)$. Importantly, a clear dose dependence was found from 0.5 to $4 \mathrm{mg} \mathrm{kg}^{-1}$ (Figure $2 \mathrm{~B} ; P<0.05$ ), suggesting the proinflammatory effect of MWCNTs under the occupational exposure setting and even under low-dose exposure setting (e.g., the environmental exposure). Afterward, all MWCNTs were subjected to I.T. administration in mice (Figure 2C). A great elevation of IL- 6 concentration was found in sera from mice treated with all MWCNTs, and the IL-6 concentration was under the detection limit in untreated mice (Figure 2C). Of these MWCNTs, P-MWCNTs, MWCNTsPEI, and MWCNTs- $\mathrm{NH}_{2}$ induced higher IL-6 production than that in mice treated with MWCNTs-PEG and MWCNTs-COOH (Figure 2C).

An important aspect of inflammatory responses to invading particles is associated with activation of inflammatory cells and further extravasation and migration of more inflammatory cells. ${ }^{[57,58]}$ For instance, activated macrophages secrete pro-inflammatory cytokines (including IL-6) to recruit more leukocytes in order to amplify the local inflammation and to initiate the systemic inflammation. ${ }^{[59-62]}$
We thus looked into macrophagic activation and leukocyte recruitment in lungs by collecting bronchoalveolar lavage (BAL) from mice responding to different MWCNTs (Figure 3A). The BAL was thoroughly collected with cold phosphate-buffered saline (PBS) after $2 \mathrm{~d}$ exposure, and was thereafter subjected to flow cytometry analysis (FACS) analysis. As shown in Figure 3A, the identity of subpopulations among these cells was closely differentiated through diverse markers. CD45 together with CD54 was used to identify recruited leukocytes from circulation. ${ }^{[54]}$ Of $\mathrm{CD} 45^{+} \mathrm{CD} 54^{+}$cells, the numbers of macrophages $\left(\mathrm{CD} 11 \mathrm{~b}^{+} \mathrm{F} 4 / 80^{+}\right.$cells $\left.^{[63]}\right)$ and neutrophils $\left(\mathrm{CD} 11 \mathrm{~b}^{+} \mathrm{GR} 1^{+}\right.$ cells $\left.{ }^{[64]}\right)$ were enriched in BAL from mice treated with MWCNTs except for MWCNTs-PEG and MWCNTs$\mathrm{COOH}$ with marginal changes (Figure 3B,C). Significant increases were observed for mice upon P-MWCNTs (seven-fold and three-fold increases, respectively) and MWCNTs- $\mathrm{NH}_{2}$ (five-fold and two-fold increases, respectively), compared to untreated mice (Figure 3B,C; $P<$ 0.05). These results together demonstrated that MWCNTs locally incurred inflammatory cell activation and further recruited additional pro-inflammatory cells including neutrophils and macrophages into lungs, especially for P-MWCNTs, whereas MWCNTs-PEG and MWCNTs$\mathrm{COOH}$ appeared rather mildly, compared to P-MWCNTs and other MWCNTs. 


\subsection{Pro-inflammatory Responses to Intravenous (I.V.) or Intraperitoneal (I.P.) Exposure of Various MWCNTs in Animals}

I.V. and I.P. administration routes are more relevant to the biomedical and accidental exposure, and are often used for understanding the mechanisms of immune responses including inflammation. ${ }^{[8,44,65-67]}$ Therefore, we performed these two exposure routes in addition to I.T. route in the current study (Figure 2A). Similar to the results from the I.T. exposure study (Figure 2), a large increase of IL-6 concentration was found in sera from mice treated with all MWCNTs under both I.V. and I.P. exposures for $2 \mathrm{~d}$, especially for P-MWCNTs (Figure 4A,B; $P<0.05$ ). Of these MWCNTs, MWCNTs-PEG and MWCNTs-COOH overall revealed a weaker ability to increase the IL-6 production than other MWCNTs (Figure 4A,B).

To substantiate the pro-inflammatory responses induced by these MWCNTs, longer exposure was carried out. Similar to the findings from the $2 \mathrm{~d}$ exposure, a significant induction of serum IL-6 was demonstrated in mice upon administration with P-MWCNTs and their derivatives following the $14 \mathrm{~d}$ exposure (Figure 4C; $P<0.001$ ). Similarly, MWCNTs-PEG
(A) In serum (I.V. 2 days)

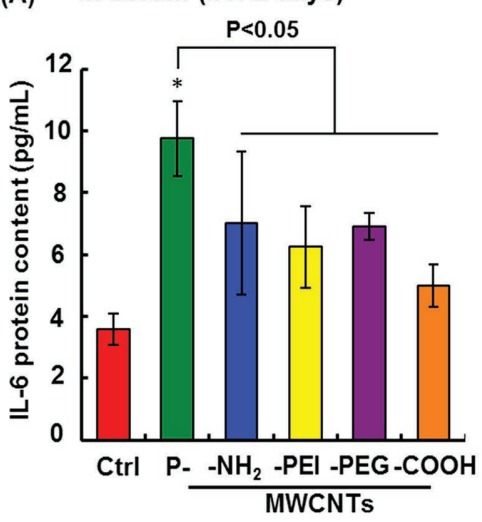

(C) In serum (I.P. 14 days)

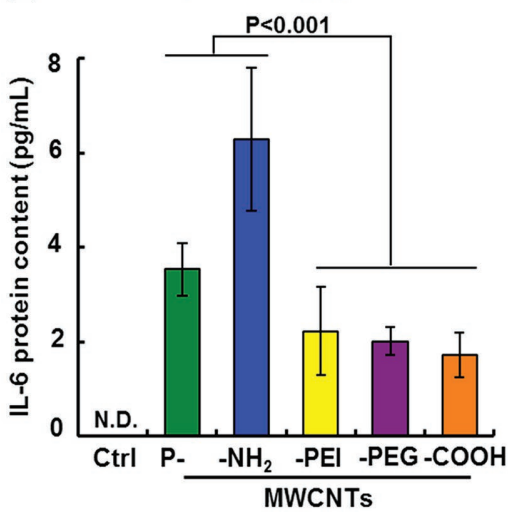

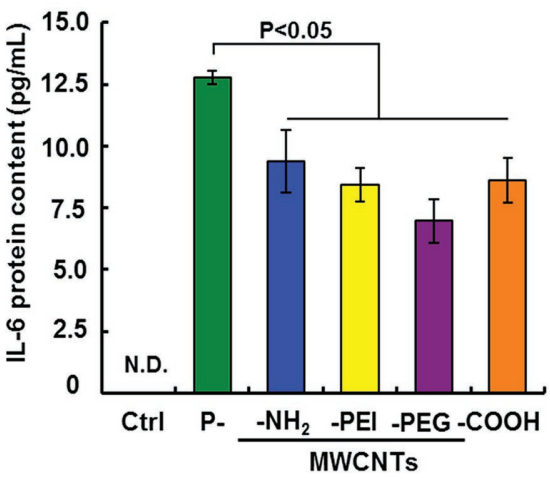

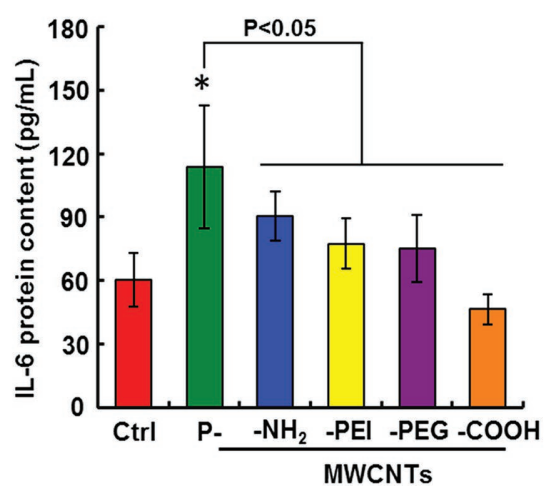

(B) In serum (I.P. 2 days)

(D) Peritoneal lavage (I.P. 14 days)

Figure 4. MWCNTS promoted the induction of IL-6 through I.V. and I.P. administration. The serum IL- 6 levels A) in mice upon I.V. administration of different MWCNTs at $4 \mathrm{mg} \mathrm{kg}^{-1}$ body weight for 2 d. Following I.P. administration of diverse MWCNTs in mice at $4 \mathrm{mg} \mathrm{kg}^{-1}$ body weight for B) $2 \mathrm{~d}$ or C,D) $14 \mathrm{~d}$, the peritoneal lavages and peripheral blood were collected afterward. The serum IL-6 levels were then determined for mice upon treatment for B) $2 \mathrm{~d}$ or C) $14 \mathrm{~d}$. D) IL-6 concentration in the total exudation proteins collected from the peritoneal cavities of mice after $14 \mathrm{~d}$ treatment. There were six mice per group $(n=6)$. N.D. denotes not detectable. Asterisk $\left({ }^{*}\right)$ indicates $P<0.05$, compared to control group. and MWCNTs-COOH promoted less increase of serum IL-6 concentration relative to other MWCNTs (Figure 4C; 0.05). Moreover, the peritoneal lavages were thoroughly MWCNT exposure overall increased the concentrations of IL-6 in peritoneal lavages relative to untreated mice $(P<$ $05)$. Consistent with the changes of serum IL-6 concentrarelative to untreated control; however, MWCNTs-COOH manifested the weakest effect (Figure 4D).

\subsection{Systemic Iron Disorders Caused by MWCNTs}

Lasting inflammation results in disordered iron homeostasis through provoking hepcidin expression by pro-inflammatory cytokines, predominantly by IL-6. ${ }^{[68]}$ Iron is an essential metal necessary for a large array of biological processes, such as heme synthesis, energy metabolism, DNA replication, and other important cellular processes. ${ }^{[69-71]}$ Hepcidin is the central hormone secreted by hepatocytes in regulating iron flow by limiting dietary iron absorption from the duodenum and iron egress from macrophages in spleen. ${ }^{[72]}$ Hepcidin exerts this function through binding to its receptor FPN (thus far the only known mammalian iron exporter) and inducing its degradation in an ubiquitin-dependent manner. ${ }^{[72]}$ Therefore, hepcidin-FPN axis prominently governs systemic iron metabolism, whereas deregulation of hepcidin expression leads to a number of types of iron disorders including iron-deficiency anemia or iron overload diseases, such as hereditary hemochromatosis and $\beta$-thalassemia.[28,73] Increased hepcidin level gives rise to limited dietary iron absorption and iron release from macrophages, resulting in reduced iron concentration in serum, associated with insufficient iron supply for HGB synthesis in erythroid cells during erythropoiesis and eventually anemia.

Thus, to scrutinize the detrimental outcomes linked to the pro-inflammatory effects upon MWCNTs, we investigated the alteration of hepatic hepcidin expression and consequential tissue iron levels in response to MWCNT treatment. We first looked at hepcidin expression changes in mice challenged by all types of MWCNTs through three exposure routes for $2 \mathrm{~d}$. As shown in Figure $5 \mathrm{~A}-\mathrm{C}$, the expression of hepatic hepcidin was greatly induced in mice upon all MWCNT treatments through I.T., I.V., and I.P. exposure $(P<0.001)$. Overall, MWCNTs-PEG 
(A) Hepatic hepcidin (I.T. 2 days)

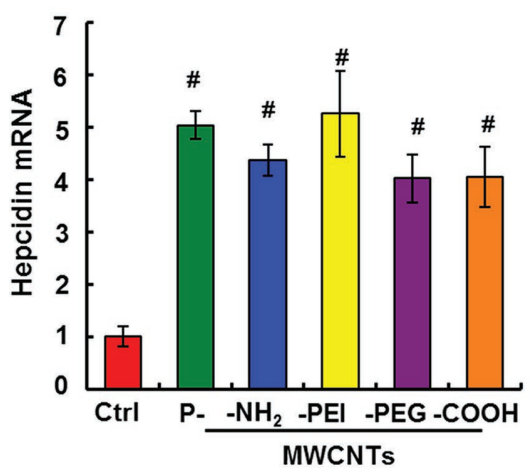

(B) Hepatic hepcidin (I.V. 2 days)

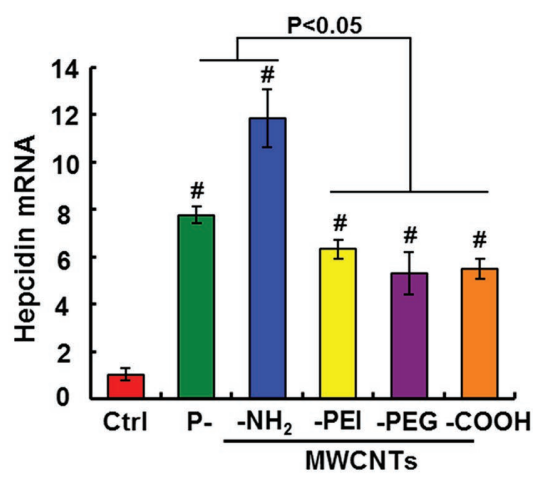

(C) Hepatic hepcidin (I.P. 2 days)

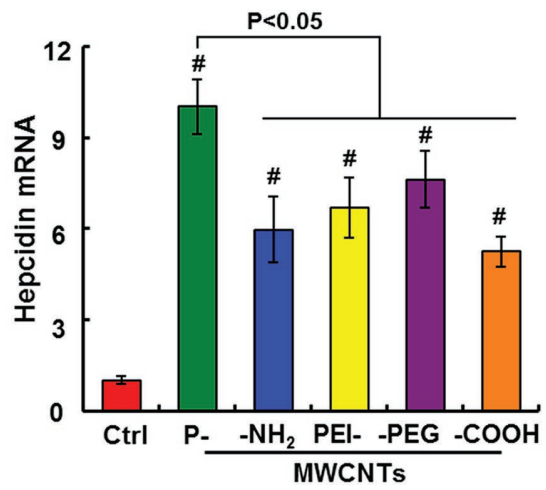

Figure 5. MWCNTs elevated hepatic hepcidin expression in mice following short-term exposure. Liver specimens were collected after MWCNT treatment for $2 \mathrm{~d}$ either through A) I.T., B) I.V., or C) I.P. administration at $4 \mathrm{mg} \mathrm{kg}^{-1}$ body weight. Relative hepatic hepcidin mRNA levels were assayed in mice post A) I.T., B) I.V., and C) I.P. administration $(n=6)$. Asterisk $\left(^{\star}\right)$ indicates $P<0.05$, and the pound sign (\#) denotes $P<0.001$, compared to control group. increase in P-MWCNT and MWCNTPEI-treated mice, compared to that in untreated mice (Figure S1C, Supporting Information). Spleen is the major organ for macrophage-conducted $\mathrm{RBC}$ recycling and iron egress for utilization in erythropoiesis, ${ }^{[74]}$ and splenic iron level is closely regulated by hepcidin. ${ }^{[27,75]}$ Meanwhile, liver iron level is not sensitive to hepcidin fluctuation. ${ }^{[20,27,75-77]}$ We found that the total liver iron content did not change significantly upon MWCNT exposure.

With respect to the short-term exposure, we obtained consistent results through I.T., I.V., and I.P. administration. In general, MWCNTs-PEG and MWCNTs-COOH were weaker to trigger IL-6 production and to alter hepcidin expression, associated with milder effects on iron homeostasis, relative to pristine and other MWCNTs. For iron homestasis, both short-term and long-term changes should be examined. ${ }^{[78,79]}$ Thereafter, we assessed the alterations of hepatic hepcidin and iron distribution under the longterm exposure. Similar to the results from the short-term treatment, all MWCNT samples elevated the levels of serum IL-6 and hepatic hepcidin to a various extent following $14 \mathrm{~d}$ treatment relative to untreated mice, as less induction in MWCNT-PEG- or MWCNT-COOHtreated mice, compared to other MWCNT and MWCNTs-COOH, especially for MWCNTs-COOH, showed a milder capability to stimulate hepcidin expression than other MWCNTs (Figure 5), analogous to the IL-6 results (Figures 2 and 4). These above results collectively demonstrated that all these three exposure routes similarly increased serum IL-6 concentration, and consequently promoted hepatic hepcidin expression. To this end, we embarked on hepcidin-determined iron metabolism in mice challenged by I.P. administration of MWCNTs. Due to a high hepcidin level in mice following MWCNT exposure, these mice accordingly manifested a decline of serum iron concentration and an increase of total splenic levels, especially for P-MWCNT-treated mice $(54 \%$ reduction in serum iron and $35 \%$ increase in total splenic iron), compared to untreated mice (Figure S1A,B, Supporting Information; $P<0.05)$. Moreover, P-MWCNTs showed the strongest capability of altering iron redistribution of all MWCNTs (Figure S1A,B, Supporting Information), consistent with the variations of hepcidin expression (Figure 5C). Meanwhile, total hepatic iron level was not significantly changed, with only $\approx 10 \%$
(A) Hepatic hepcidin (I.P. 14 days)
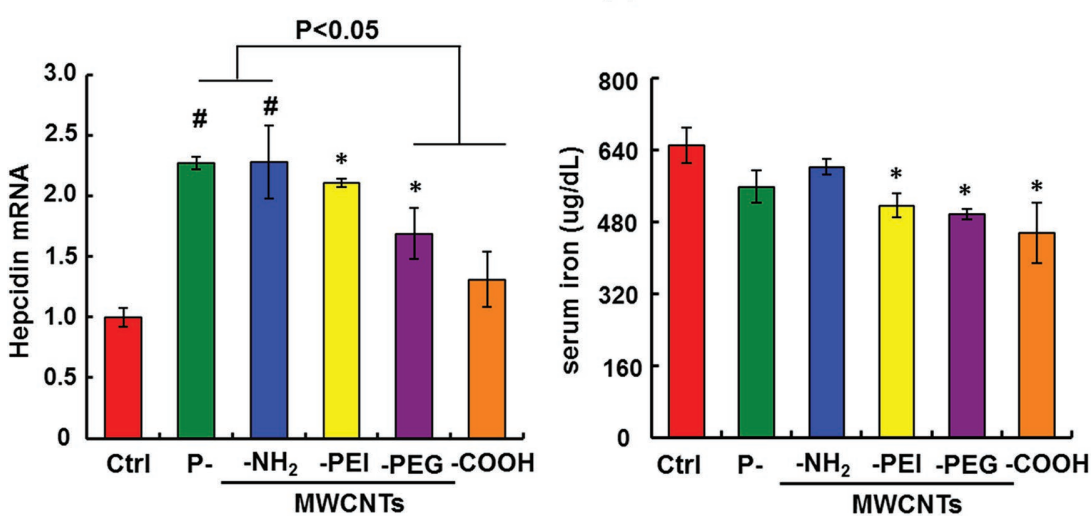

Figure 6. MWCNTs altered iron distribution following a long-term treatment. Hepcidin MWCNTs at $4 \mathrm{mg} \mathrm{kg}^{-1}$ body weight for $14 \mathrm{~d}$. A) Relative hepcidin expression level in liver. B) Serum nonheme iron content. There were six mice in each group $(n=6)$. Asterisk $\left.{ }^{*}\right)$ indicates $P<0.05$, and the pound sign (\#) denotes $P<0.001$, compared to untreated control. expression and iron levels were examined in mice following I.P. administration of different 
materials provoked proinflammatory responses and altered systemic iron homeostasis, although to a various extent. Since carboxylation is the most widely used functionalization form for CNTs in biomedical applications, ${ }^{[80-82]} \mathrm{MWCNTs-COOH}$ was selected in the following detailed mechanistic studies.

\subsection{MWCNT Exposure Caused Al}

Systemic iron homeostasis is strictly modulated to ensure the balance between iron supply and utilization in mammals; $;{ }^{[83]}$ however, inflammation could significantly alter iron status, leading to AI. ${ }^{[84]} \mathrm{AI}$ (formerly also called anemia of chronic disease or anemia of chronic disorders) is usually a mildly to moderately severe anemia that develops in the setting of infection, inflammatory diseases or malignancy. ${ }^{[85,86]} \mathrm{A}$ hallmark of $\mathrm{AI}$ is the disturbance of iron homeostasis, with a diversion of iron from the circulation into storage sites within the reticuloendothelial system, which results in insufficient supply of iron to erythroid progenitor cells during RBC formation. ${ }^{[87,88]}$ Since considerable inflammation and changes of iron status were demonstrated in MWCNT-treated mice, as described above, we postulated that these mice might develop AI. To test our hypothesis, complete blood count (CBC) analysis was performed. Consistent with the finding on systemic inflammation induced by MWCNTs, a remarkable increase was observed for the numbers of total white blood cells (WBCs, by 70\%), lymphocytes (LYMs, by 67\%), and neutrophil (NE, 67\%) in peripheral blood from mice following MWCNT-COOH administration for $2 \mathrm{~d}$, compared to those of untreated mice (Figure 7A; $P<0.05$ ). Meanwhile, the RBC number and $\mathrm{HGB}$ content were reduced by $\approx 11 \%$ and $\approx 8 \%$, respectively, in MWCNT-COOH-treated mice, compared to untreated control (Figure 7A), suggesting an association between MWCNT-induced inflammation and the reduction of RBC and HGB. Since the development of AI is a chronic process, we looked into the $\mathrm{CBC}$ results after $14 \mathrm{~d}$ exposure. As shown in Figure 7A, further increased counts of WBC, LYM, and NE were observed in mice following MWCNT-COOH treatment for $14 \mathrm{~d}$, compared to untreated mice and mice with MWCNT-COOH treatment for $2 \mathrm{~d}(P<0.05)$, indicting continuous inflammation in these mice. As a consequence, the RBC number and HGB count were further declined by more than $13 \%$ in MWCNT-COOH-treated mice, compared to untreated mice (Figure 7A; $P<0.05$ ). Moreover, as discussed in Figure $6 \mathrm{~B}$, the serum iron level was significantly reduced by $30 \%$ in mice following MWCNT-COOH exposure, with a concurrent increase of total splenic iron (by 10\%; Figure S2, Supporting Information), compared to untreated mice. Our combined results were consistent with the previous findings on $\mathrm{AI}$ in mice, ${ }^{[89,90]}$ and we thus concluded that MWCNT$\mathrm{COOH}$ exposure induced AI due to insufficient iron supply for erythropoiesis under MWCNT-COOH-provoked chronic inflammation, in agreement with the definition of AI. ${ }^{[79,91]}$

\subsection{MWCNTs-COOH Induced Splenomegaly and Extramedullary Erythropoiesis in Spleen}

Thereafter, we studied the implications under AI induced by MWCNTs. Spleen is the center of the body's endocrine metabolic and immune network with multiple functions. ${ }^{[92]}$ It is also the location for RBC renewal through the engulfment of aged RBCs by macrophages, ${ }^{[93]}$ and the organ for extramedullary erythropoiesis under anemia, associated with enlarged spleen size (namely splenomegaly). ${ }^{[94,95]}$ Figure $7 \mathrm{~B}$ shows an enlargement of the spleen size for mice after MWCNT treatment for $14 \mathrm{~d}$, and quantitative data revealed more than $30 \%$ increase of spleen weight, indicative of the occurrence of splenomegaly, compared to untreated mice (Figure 7C; $P<0.001$ ).

To validate the mobilization of erythropoietic activity into spleens, histological studies with hematoxylin-eosin (H\&E) staining were carried out to examine erythropoiesis in spleens for mice under MWCNT treatment. As shown in Figure 7D, spleen sections manifested pronounced increase of erythroblasts in spleens from mice upon MWCNT exposure, as evidenced by the expansion of erythroblasts in the red pulp (denoted by yellow arrows). Furthermore, FACS analysis was performed to confirm the expansion of splenic erythroblasts. Ter119 is a representative surrogate to label erythroid cells from proerythroblasts to mature erythrocytes. ${ }^{[96,97]}$ As shown in Figure 7E,F, the proportion of Ter $119^{+}$cells was increased by 2.3-fold in the total cells isolated from spleens of mice upon MWCNT exposure, compared to those from spleens in untreated mice $(56.4 \%$ vs $25.0 \% ; P<0.001)$, indicting a substantial accumulation of erythroid precursors in the spleen. Moreover, the fluorescence intensity was increased by more than three fold for gated Ter $119^{+}$cells from mice upon MWCNT treatment, relative to that from mice without MWCNT treatment (Figure 7F; $P<0.001$ ). These results collectively demonstrated that MWCNT treatment induced splenomegaly and extramedullary erythropoiesis in spleens, analogous to the occurrence of AI.

\subsection{MWCNTs-COOH Provoked Inflammation and Macrophage Accumulation in Liver and Spleen}

To substantiate the induction of hepcidin by inflammation in response to MWCNTs, we further looked into the local inflammation in liver. Previous studies have demonstrated that liver is the prominent site for nanoparticle accumulation. ${ }^{[98-100]}$ Similar to previous reports, ${ }^{[101-103]}$ dark dots (representative of CNTs) could be visualized in livers from mice treated with MWCNTs-COOH for $14 \mathrm{~d}$ (denoted by arrows in Figure 8A), indicting the translocation of CNTs to liver. Meanwhile, the alanine transaminase (ALT) level and aspartate aminotransferase (AST) level were not significantly changed (Figure 8A, the lower panel), suggesting no significant hepatotoxicity induced by MWCNTs-COOH. ${ }^{104,105]}$ Nonetheless, histological examination showed substantial infiltration of macrophages around hepatic sinusoids and central veins (Figure 8B, denoted by yellow arrows). To verify this finding, immunohistochemistry was performed in liver sections with an F4/80 antibody ( $\mathrm{Ab}$, a representative marker for macrophages $\left.{ }^{[106]}\right)$. As shown in Figure $8 \mathrm{C}$, a larger number of F4/80-positive cells (shown in yellow-brown color, indicted by arrows) were found in the liver sections from mice upon MWCNT treatment in comparison to those 
(A)

$\mathrm{CBC}$ analysis

\begin{tabular}{|c|c|c|c|}
\hline Cell type & $\begin{array}{c}\text { Untreated } \\
\text { Ctrl }\end{array}$ & $\begin{array}{c}\text { MWCNTs-COOH } \\
(2 \text { days })\end{array}$ & $\begin{array}{c}\text { MWCNTs-COOH } \\
(14 \text { days })\end{array}$ \\
\hline WBC $\left(10^{9} / \mathrm{L}\right)$ & $3.13 \pm 0.39$ & $5.33 \pm 0.17^{\#}$ & $7.48 \pm 0.64^{\#}$ \\
\hline LYM (10\%/L) & $1.45 \pm 0.20$ & $2.42 \pm 0.21^{*}$ & $2.62 \pm 0.26^{*}$ \\
\hline NE (109/L) & $1.47 \pm 0.17$ & $2.45 \pm 0.21^{*}$ & $4.62 \pm 0.66^{\#}$ \\
\hline RBC (10 $12 / L)$ & $10.03 \pm 0.65$ & $9.07 \pm 0.13$ & $8.82 \pm 0.33^{\#}$ \\
\hline HGB (g/L) & $155.17 \pm 9.97$ & $144.25 \pm 1.80$ & $136.20 \pm 5.10^{\#}$ \\
\hline
\end{tabular}

(B)

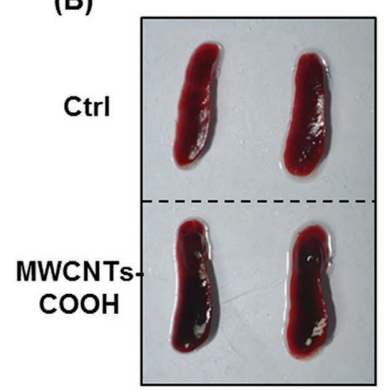

(D)

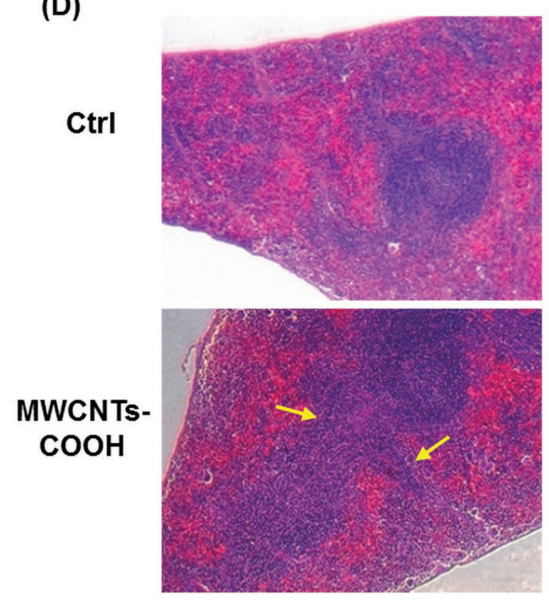

(C)

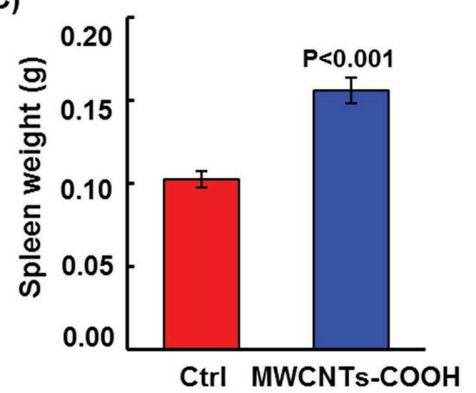

(E)
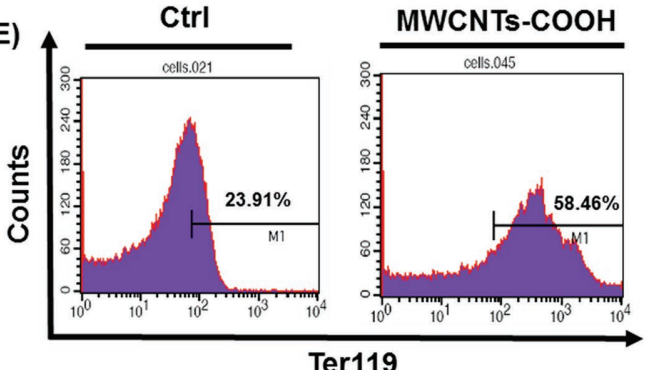

(F)

\begin{tabular}{c|c|c}
\hline M1 & \% Gate & Geo mean \\
\hline Ctrl & $25 \pm 1.51$ & $109 \pm 40.96$ \\
MWCNTs-COOH & $56 \pm 2.566^{\#}$ & $351 \pm 43.966^{\#}$ \\
\hline
\end{tabular}

Figure 7. MWCNT exposure impeded RBC formation and caused splenomegaly and extramedullary erythropoiesis. A) CBC analysis of peripheral blood from mice following I.P. MWCNT-COOH administration at $4 \mathrm{mg} \mathrm{kg}^{-1}$ body weight for 2 and $14 \mathrm{~d}$. Post MWCNT-COOH exposure for $14 \mathrm{~d}$, spleens were collected for further examination: B) representative spleen images, C) the average weight of spleens $(n=6)$, D) representative H\&E staining images of spleen sections. Yellow arrows indicate the expansion of erythroblasts in red pulp. Original magnification: 200x. E) FACS analysis of erythroid cells in spleens by sorting Ter $119^{+}$cells. F) Quantitative data for the proportions of Ter $119^{+}$cells and the average fluorescence intensity of Ter119+ cells (Geo mean) $(n=6)$.

from untreated mice, and quantified data showed twofold increase (Figure 8D; $P<0.001$ ). Meanwhile, the expression of liver C-reactive protein (CRP) was elevated by more than twofold, relative to untreated mice, as reflected by quantitative reverse transcription-polymerase chain reaction (qRTPCR) analysis (Figure $8 \mathrm{E} ; P<0.05$ ). CRP is produced by hepatocytes, in response to inflammatory cytokines, such as IL-6, and it has been recognized as a major surrogate for liver infection and inflammation. ${ }^{[107]}$ Of note, IL-6 is the predominant cytokine in regulating hepatic hepcidin expression and subsequent iron homeostasis, as discussed in our recent review paper. ${ }^{[68]}$ These results thus demonstrated robust proinflammatory responses in liver upon MWCNT exposure, and also highlighted the contribution of hepatic inflammation to hepcidin regulation and inflammation-associated anemia.

In addition to liver, spleen is another important organ in response to inflammation. For example, macrophages are crucial for erythroid differentiation during extramedullary erythropoiesis in spleen by forming erythroid islands. ${ }^{[108-110]}$ Since we observed splenomegaly and significant extramedullary 
(A)

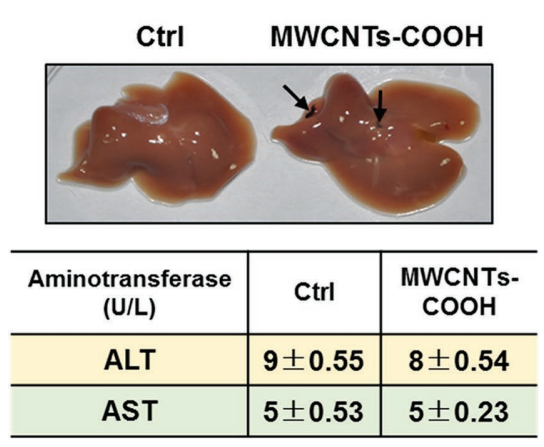

(B)

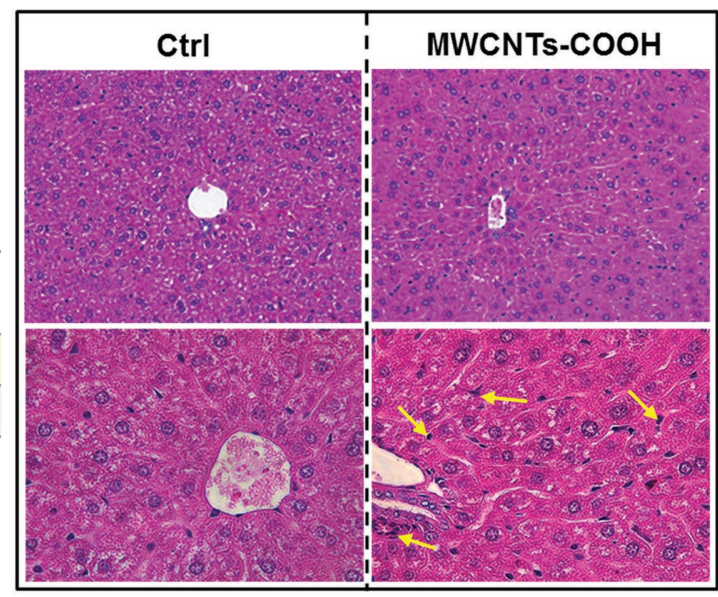

(C)

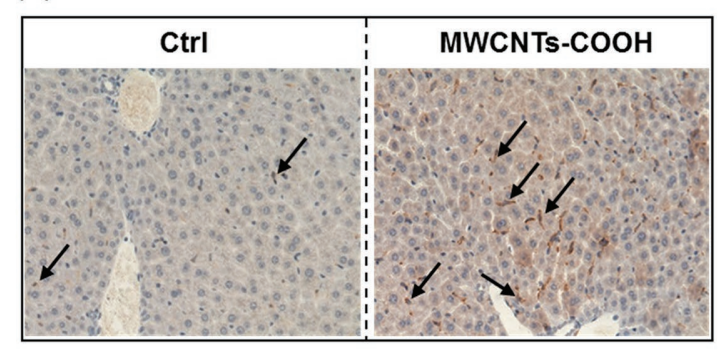

(E) Hepatic CRP (I.P. 14 days)

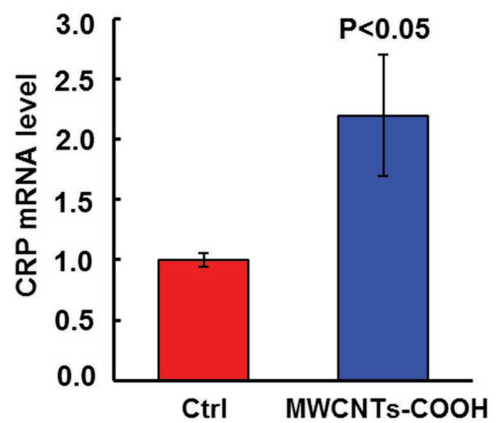

(D)

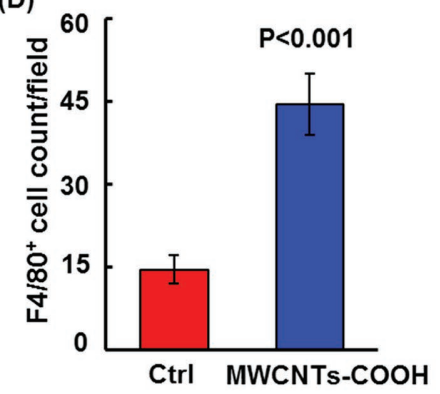

Figure 8. MWCNTs- $\mathrm{COOH}$ provoked inflammation and macrophage accumulation in liver. Livers were collected for close investigation post I.P. MWCNT- $\mathrm{COOH}$ exposure at $4 \mathrm{mg} \mathrm{kg}^{-1}$ body weight for $14 \mathrm{~d}$. A) Representative liver images. Arrows indicate MWCNT accumulation (shown in dark dots) in livers. Aminotransferase (including ALT and AST) concentrations in sera were listed in the lower panel $(n=6)$. B) Representative images of liver sections with $\mathrm{H} \& \mathrm{E}$ staining. Yellow arrows denote macrophages. The original magnification for the upper panel and the lower panel is $200 \times$ and $400 \times$, respectively. C) Immunohistochemical staining of liver sections with an F4/80 Ab. F4/80 positive cells are shown in brown (indicted by black arrows). Original magnification, 200x. D) Quantitative data for the number of F4/80 positive cells per field $(n=8)$. E) Relative CRP expression levels in liver $(n=6)$.

erythropoiesis in MWCNT-treated mice, we postulated that there was also macrophage accumulation in spleen. First, erythrocytes were lysed in the total spleen cell suspensions with RBC lysis solution, and thereafter all other cells were collected and counted for the following studies. As shown in Figure 9A, the number of collected cells was increased by twofold in spleens from MWCNT-treated mice, compared to that in spleens from untreated mice $(P<0.001)$. The FACS analysis indicated that the proportion of F4/80-positive cells was more than two times higher in the total spleen cells from mice treated with MWCNTs, relative to that from untreated control (Figure 9B; $P<0.05$ ). Moreover, the total number of
F4/80-positive cells was greatly increased by four times in spleens of mice upon MWCNT treatment, compared to that in spleens of untreated mice (Figure 9C; $P<0.001$ ). To verify the activation status of splenic macrophages, IL- 6 expression level was determined. As shown in Figure 9D, the IL-6 level was elevated by over $60 \%$ in splenic cells from MWCNTtreated mice, compared to that from untreated mice $(P<0.001)$, suggesting enhanced activation of macrophages in spleens upon MWCNT exposure. Together, we demonstrated remarkable inflammation and macrophage infiltration in spleens of mice in response to MWCNTs, indicating that the increased number of pro-inflammatory cells (e.g., 
(A)
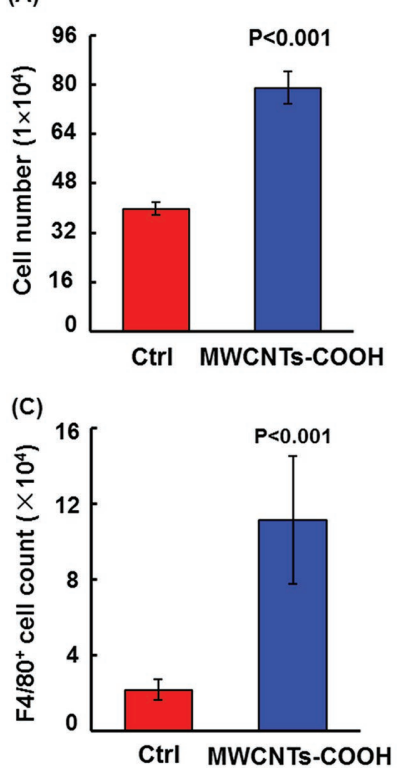

Figure 9. MWCNTs-COOH incurred inflammation and macrophage accumulation in spleens. After I.P. administration for $14 \mathrm{~d}$, spleens were dissected for the preparation of single cell suspension. A) Cell number counting of nonerythroid cells after RBC lysis. B) The proportions of F4/80 positive cells of the total nonerythroid cells from the spleen single cell suspensions. C) The total number of $F 4 / 80$ positive cells within the total nonerythroid splenic cells. D) Relative IL-6 expression levels in spleen. There were six mice in each group $(n=6)$.

macrophages) also contributed to the occurrence of splenomegaly in mice upon MWCNTs.

\subsection{MWCNTs-COOH Induced Macrophagic Activation and Recruited Proinflammatory Cells}

Furthermore, to decipher the mechanism underlying MWCNT-induced macrophagic activation and magnification of the proinflammatory responses, we elaborated macrophagic activation and cell recruitment in abdominal cavities of mice following I.P. administration of MWCNTs-COOH (Figure 10). The peritoneal lavages were thoroughly collected with cold PBS after $2 \mathrm{~d}$ exposure, and were thereafter subjected to protein analysis, cell number counting, and FACS analysis. The total protein concentration was 2.7 times higher in lavages from MWCNT-treated mice than that in untreated control group (Figure 10A; $P<0.001$ ). Importantly, the concentration of IL- 6 was increased by ten times in lavages collected from mice treated with MWCNTs-COOH, compared to that in lavages from untreated mice (Figure 10B; $P<0.001)$. These findings suggested that MWCNTs induced significant macrophagic activation and proinflammatory responses in abdominal cavities.

Pro-inflammatory cells were thereafter determined through FACS analysis. Figure 10C shows greater than fivefold increase of the total cell number in peritoneal lavages from CNT-treated mice, compared to that from untreated mice $(P<0.001)$. The identity of subpopulations among these cells was closely differentiated through diverse markers.
CD45 together with CD54 was used to identify recruited leukocytes from circulation. ${ }^{54]}$ There was 13 -fold increase of $\mathrm{CD} 45^{+} \mathrm{CD} 54^{+}$cells in mice upon MWCNT-COOH treatment, compared to the control (Figure 10D; $P<0.001$ ). From $\mathrm{CD} 45^{+} \mathrm{CD} 54^{+}$cells, the number of $\mathrm{CD} 11 \mathrm{~b}^{+}$subpopulation was increased by $\approx 90$ times in response to CNTs, relative to the untreated control (Figure 10E; $P<0.001$ ). Within the $\mathrm{CD}_{11 \mathrm{~b}^{+}}$subpopulation, the numbers of macrophages $\left(\mathrm{CD} 11 \mathrm{~b}^{+} \mathrm{F} 4 / 80^{+}\right.$cells $\left.^{[63]}\right)$ and neutrophils $\left(\mathrm{CD} 11 \mathrm{~b}^{+} \mathrm{GR} 1^{+}\right.$ cells $\left.{ }^{[64]}\right)$ were enriched by 18 -fold and 164 -fold, respectively, in lavages from CNT-treated mice, compared to those from untreated mice (Figure 10F,G; $P<0.001$ ). These results together demonstrated that MWCNTs-COOH locally stimulated macrophagic activation to enhance pro-inflammatory responses in peritoneal cavities by recruiting additional proinflammatory cells including neutrophils and macrophages.

\subsection{MWCNTs Stimulated Hepcidin Induction through Macrophage-Derived IL-6}

To gain more insights into the underlying molecular mechanisms, in vitro experiments were carried out. First, it is important to know the relevance of in vitro dose to in vivo dosimetry. The mouse exposure was performed from 0.5 to $4 \mathrm{mg} \mathrm{kg}-1$ body weight. Take $2 \mathrm{mg} \mathrm{kg}^{-1}$ body weight as an example for justification. The mouse exposure at $2 \mathrm{mg} \mathrm{kg}^{-1}$ is equivalent to $1 \mathrm{mg} \mathrm{m}^{-2}$ of MWCNTs in the mouse lung considering the alveolar surface area being $0.05 \mathrm{~m}^{2}$. Assuming that the in vitro MWCNT samples are homogeneously distributed in the tissue culture dish and the thickness of cell layer is $10 \mu \mathrm{m}$, the in vitro cell exposure concentration is calculated to be $100 \mu \mathrm{g} \mathrm{mL} \mathrm{m}^{-1}$. The concentrations we used for in vitro experiments were all covered in this concentration range, comparable to the dose range in the mouse experiments. Thus, the doses of MWCNTs used in cultured cells and in mice in this study are comparable to occupational exposure in humans. It should be noted that the rationale for the selection of these in vitro concentrations is only based on the estimation of the above assumptions; however, the actual exposure concentration must be higher than these. ${ }^{[51,53,111]}$

To confirm the pro-inflammatory effects of MWCNTs on macrophages, a macrophage cell line J774.A1 was employed. The concentrations from 25 to $100 \mu \mathrm{g} \mathrm{mL}-1$ were selected for cellular treatment (Figure S3, Supporting Information). As shown in Figure 11A,B, a significant increase of proinflammatory cytokines including IL-6 and tumor necrosis factor (TNF)- $\alpha$ was found in J774.A1 cells upon MWCNTs$\mathrm{COOH}$ at 25,50 , and $100 \mu \mathrm{g} \mathrm{mL}^{-1}(P<0.001)$, clearly in a dose-dependent manner, in parallel to the in vivo results, as discussed above (Figure 2B). Of note, for TNF- $\alpha$ production, $50 \mu \mathrm{g} \mathrm{mL}^{-1}$ MWCNTs-COOH appeared to have reached the maximum induction (Figure 11B). Meanwhile, all MWCNTs were also subjected to the detection of TNF- $\alpha$ in J774.A1 cells. The concentration assessment showed a significant induction of TNF- $\alpha$ in supernatants collected from J774.A1 cells upon all MWCNTs at $25 \mu \mathrm{g} \mathrm{mL}{ }^{-1}$ for $24 \mathrm{~h}(P<0.05)$, especially for P-MWCNTs and MWCNTs-PEI with more than two fold increase (Figure S4, Supporting Information; 
(A)

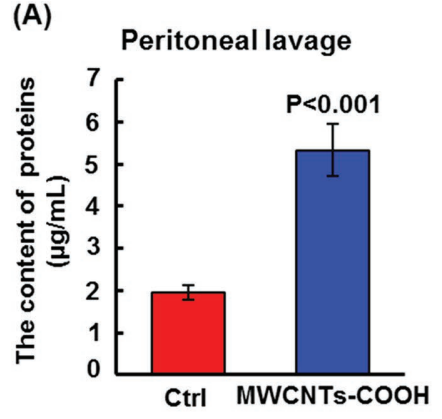

(D)

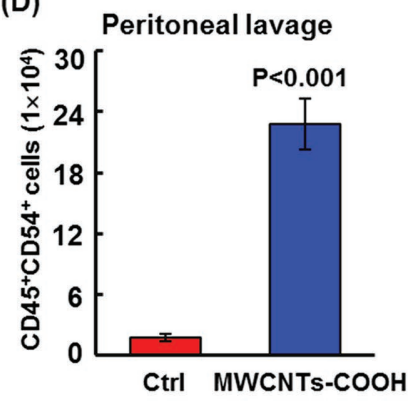

(F)

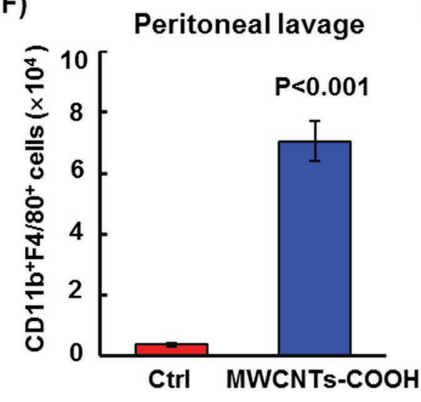

(B)

Peritoneal lavage

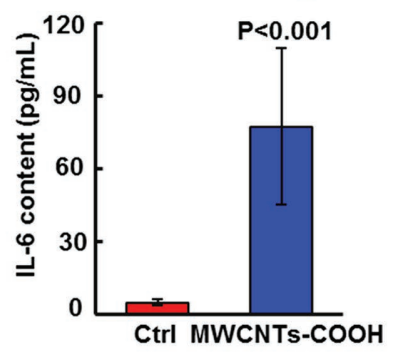

(E)

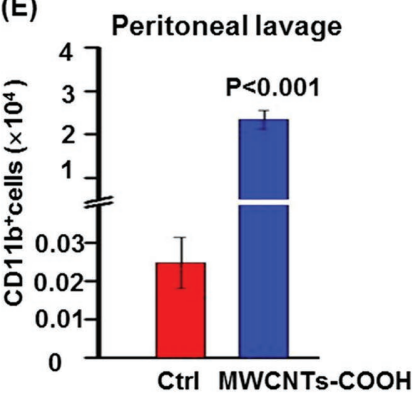

(G)

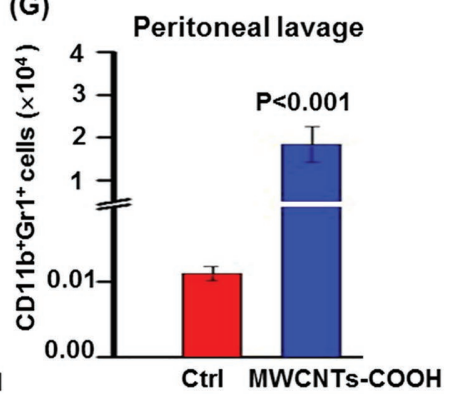

(C)

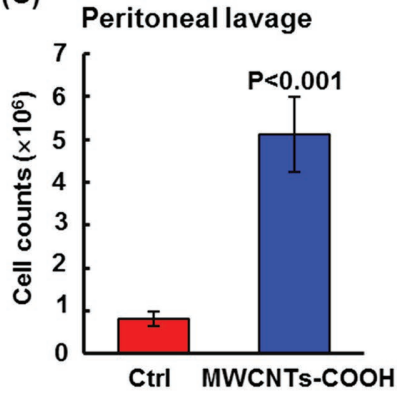

Figure 10. MWCNTs-COOH stimulated pro-inflammatory responses in peritoneal cavity. Cell sorting analysis, subpopulation determination, and cytokine concentrations in peritoneal lavages collected from mice following I.P. administration of MWCNTs-COOH for 14 d. A) Average content of total exudation proteins collected from the peritoneal cavities. B) IL-6 concentrations in the total exudation proteins in peritoneal lavages. C) Cell numbers of nonerythroid cells in peritoneal lavages. D) Number of CD $45^{+} C D 54^{+}$cells in peritoneal lavages. E) Number of total CD11 $b^{+}$cells among $\mathrm{CD} 45^{+} \mathrm{CD} 54^{+}$population. F) Number of CD11 b+F4/80+ subpopulation of CD $45^{+} \mathrm{CD} 54^{+}$population. G) Number of CD11 $\mathrm{b}^{+} \mathrm{GR} 1^{+}$subpopulation among $\mathrm{CD} 45^{+} \mathrm{CD} 54^{+}$population. There were six biological replicates per group $(n=6)$.

$P<0.001)$. Thus, MWCNTs stimulated robust macrophagic activation in spite of slight cytotoxicity.

Since our data showed significant accumulation of CNTs in livers (Figure 8A), we next aimed to figure out whether there might be a direct effect of CNTs on hepatocytes for the induction of hepcidin. To uncover the relationship between hepatocytes and macrophages under CNT exposure, hepatocyte, and macrophage cell lines were employed. HepG2 cells are widely accepted for the study of hepcidinand iron-related investigation, and these cells represent an ideal model in investigating hepcidin regulation upon exotic stimuli. ${ }^{[12]}$ The cytotoxicity to HepG2 cells was screened through the Live/Dead assay in these cells upon MWCNT$\mathrm{COOH}$ treatment. Sublethal concentrations at 20 and $40 \mu \mathrm{g} \mathrm{mL}{ }^{-1}$ were selected for the exposure studies in HepG2 cells (Figure S5, Supporting Information). MWCNT treatment greatly repressed hepcidin by $37 \%$ and $55 \%$ in HepG2 cells at 20 and $40 \mu \mathrm{g} \mathrm{mL} \mathrm{mL}^{-1}$, respectively (Figure 11C; $P<$ 0.001). In light of this result, we hypothesized that the induction of hepcidin was accounted for (at least partially) by proinflammatory cytokines from macrophages induced by CNTs. To address this hypothesis, we deliberately set up an experiment to figure out the source in determining hepcidin induction; the culture medium from J774.A1 cells with or without MWCNT exposure was used to treat HepG2 cells (Figure 11D). As shown in Figure 11E, there was an increase of hepcidin expression (by 29\%) in HepG2 cells with culture medium from MWCNT-COOH-treated J774.A1 cells, compared to that in HepG2 cells with culture medium from J774. A1 cells without MWCNT-COOH treatment $(P<0.05)$. To substantiate this finding, we added a murine hepatocyte cell line, Hepa1-6. ${ }^{[113]}$ Consistent with the results on HepG2 cells, there was a substantial induction of hepcidin expression (by $75 \%$ ) in Hepa1-6 cells with culture medium from MWCNTtreated J774.A1 cells, compared to that in Hepa1-6 cells with culture medium from untreated cells (Figure 11F; $P<0.05$ ). These data further highlighted the molecular mechanism: the induction of hepcidin was, at least partially, attributed to proinflammatory cytokines (especially, IL-6) from macrophages upon MWCNTs. 
(A) J774.A1 cells

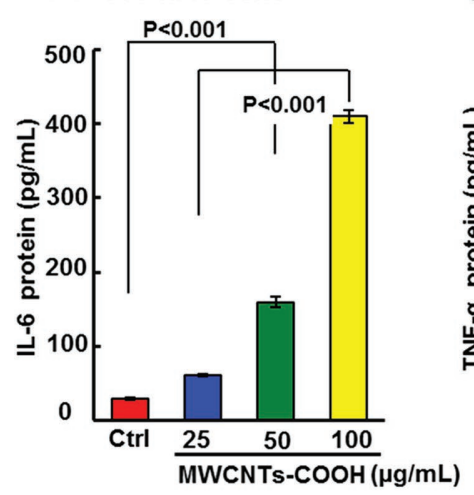

(D)

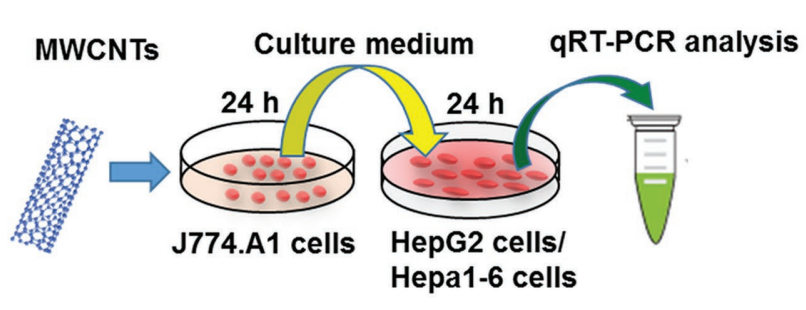

(F) Hepa1-6 cells

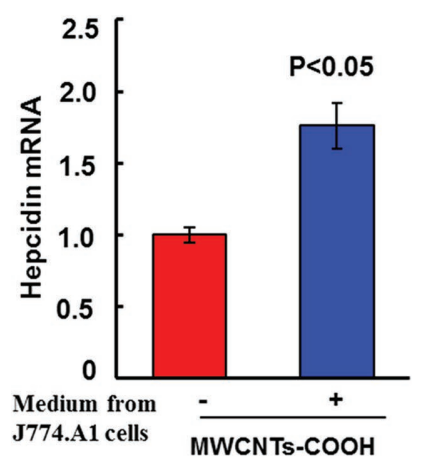

(G)
(B) J774.A1 cells

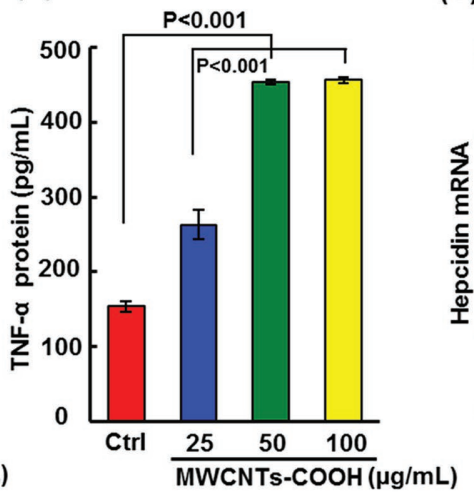

(C) HepG2 cells

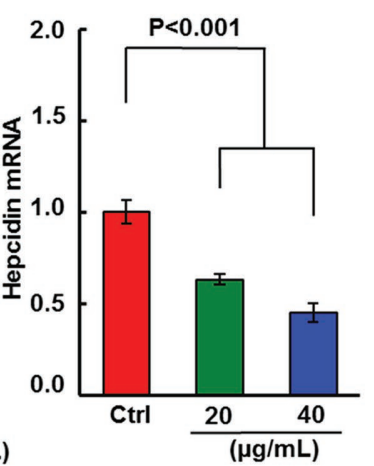

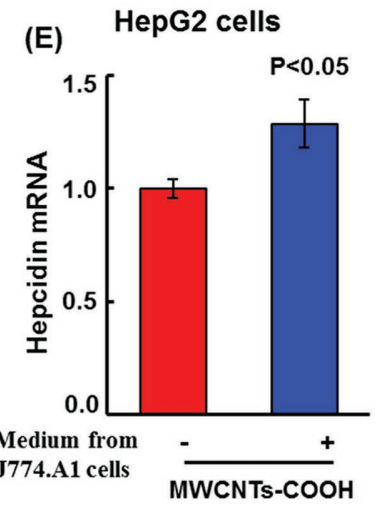

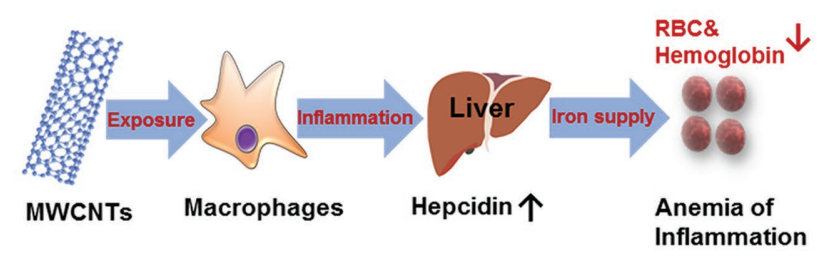

Figure 11. MWCNTs- $\mathrm{COOH}$ promoted hepcidin production through macrophage-derived inflammatory cytokines. Concentrations of A) IL-6 and B) TNF- $\alpha$ in supernatants collected from J774.A1 cell culture medium after treatment with MWCNTs-COOH at 25,50 , and $100 \mu \mathrm{g} \mathrm{mL} \mathrm{L}^{-1}$ for $24 \mathrm{~h}$. C) Relative hepcidin levels in HepG2 cells upon 20 and $40 \mu \mathrm{gL}^{-1}$ MWCNTs-COOH for $24 \mathrm{~h}$. D) A schematic diagram depicting the analysis for the evaluation of hepcidin production in HepG2 and Hepa1-6 cells in response to the stimulation of culture medium from J774.A1 cells. Relative hepcidin expression E) in HeG2 cells and F) in Hepa1-6 cells with culture medium from MWCNT-COOH-treated J774.A1 cells at $25 \mu \mathrm{g} \mathrm{mL} \mathrm{L}^{-1}$ for $24 \mathrm{~h}$, relative to those with culture medium from J774.A1 cells without MWCNT-COOH treatment. There were six biological replicates per group $(n=6)$. $\mathrm{G})$ A schematic diagram deciphering the mechanism responsible for the indirect effects of MWCNTs: disordered iron homeostasis and Al through inflammatory pathway.

\section{Discussion}

There has been no study on the potential effects on iron metabolism and RBC formation upon exposure to CNTs thus far. In this study, in addition to using a collection of CNTs to shed light on the relationship between CNT modification and secondary toxicity, we also aimed to elucidate the cascade of events: the initiating event and the subsequent key events necessary for the development of phenotypes, namely CNT-induced pro-inflammatory effects on iron homeostasis and $\mathrm{RBC}$ formation, which are linked to AI. Therefore, the current study is the first report on AI in animals caused by CNTs.

We here uncovered the pro-inflammatory effects of MWCNTs both systemically and locally, as evidenced by the induction of pro-inflammatory cytokines in sera and in lavages from abdominal cavities, recruitment of proinflammatory leukocytes into exposure sites (lung and peritoneal cavity), infiltration of pro-inflammatory leukocytes in tissues (e.g., liver and spleen), and local inflammation, such as hepatic inflammatory responses (as reflected by increased CRP expression). Furthermore, all types of 
MWCNTs could induce such a stimulatory effect, but to a variety of extent. MWCNTs-PEG and MWCNTs-COOH provoked much weaker pro-inflammatory responses. Thus, in light of these findings, MWCNTs-PEG and MWCNTs$\mathrm{COOH}$ are more biocompatible and safer than pristine MWCNTs and other types of MWCNTs with different functionalization including MWCNTs- $\mathrm{NH}_{2}$ and MWCNTsPEI. Meanwhile, all MWCNTs including MWCNTs-PEG and MWCNTs-COOH did stimulate hepcidin expression due to IL-6 induction, whereas MWCNTs-PEG and MWCNTs-COOH generally induced milder variations of hepcidin expression relative to other MWCNTs. As a result, iron metabolism was affected due to deregulated hepcidin level in mice upon these MWCNTs in both short-term and long-term exposure settings. In other words, the disturbance of iron homeostasis is the secondary adverse effect to MWCNT-stimulated inflammation. In fact, treatment with MWCNTs-PEG and MWCNTs-COOH did alter iron distribution. $\mathrm{COOH}$ or PEG functionalization could be considered as a general approach to increase biocompatibility and to reduce adverse impact of carbonaceous materials including single-wall CNTs, ${ }^{[114]}{ }^{\text {MWCNTs, }}{ }^{[115]}$ and graphene oxides. ${ }^{[116,117]}$ In terms of the fundamental nano-bio interaction, it is believed that a few mechanisms are attributed to $\mathrm{COOH}$ or PEG functionalization-determined improvement to biosafety. On one hand, the functionalization through $\mathrm{COOH}$ or PEG could enhance the suspension property of carbonaceous materials in biological media and make the particles less reactive to biomolecules. ${ }^{[118,119]}$ On the other hand, this modification could reduce the association of nanoparticles with cell membrane (which is usually negatively charged) due to electrostatic repulsion. ${ }^{[120,121]}$ Additionally, we observed slight differences in the above effects among exposure routes, presumably attributing to the distinct mechanisms underlying the translocation, cellular uptake, biodistribution, and biological activities of foreign particles upon different exposure ways. ${ }^{[122-124]}$ Nonetheless, our combined data depicted the secondary toxicity of MWCNTs in disturbing systemic iron homeostasis through inflammatory pathway, and, nonetheless, PEG and $\mathrm{COOH}$ modifications could ameliorate such secondary toxicity. In parallel to the current study, we recently reported a novel secondary toxicity of carbon nanotubes: synovial inflammation due to carbon nanotube-induced systemic inflammation. ${ }^{[29]}$ Considering the secondary toxicity, especially under long-term exposure, more investigations are needed to evaluate the biosafety of MWCNTs, regardless of surface modifications. Meanwhile, we found that MWCNTs-COOH and MWCNTsPEG induced weaker stimulatory effects on serum IL-6 and hepcidin expression, but with more disruption to iron homeostasis at $14 \mathrm{~d}$. However, this does not mean that there were discrepancies on IL-6-hepcidin and iron disruption for MWCNTs-COOH and MWCNTs-PEG, because IL-6 and hepcidin levels dynamically changed during the exposure process and their levels on day 14 were not the indictor of the whole exposure duration. As reported previously, ${ }^{[29,89,125]}$ pro-inflammatory responses (e.g., production of pro-inflammatory cytokines) and hepcidin induction would reach a maximum 1-2 d postforeign pathogen invasion; these increases would significantly drop after the maximum induction and even lower down to the baseline levels after 14 d. ${ }^{[79,126]}$ Since iron homeostasis is a dynamic process subjected to the modulation of diverse mechanisms, ${ }^{[78,127]}$ the iron parameters are finally determined by the changes of hepcidin and other mechanisms, but not the final end-point hepcidin level during the long-term exposure. Although we demonstrated that IL-6-hepcidin signaling played an important role in the regulation of iron homeostasis upon MWCNTs, inflammation-driven hepcidin is not the sole pathway to regulate iron homeostasis, and other pathways are also important in iron homeostasis, especially for a longterm duration. To this end, we could not rule out other possibilities. Under the circumstances, ferritin-mediated iron transportation and distribution, ${ }^{[128-130]}$ erythroid-demanddrived iron redistribution, ${ }^{[79,131]}$ and bone morphogenetic proteins (BMPs)-conducted hepcidin regulation ${ }^{[132,133]}$ may also be altered by MWCNTs. Additionally, there may be a likely direct impact of MWCNTs on iron homeostasis, such as iron absorption, storage, and utilization, which could also disturb iron distribution. For instance, CNTs are prone to accumulate in liver, and liver is also the major secondary target organ, ${ }^{[134]}$ where CNTs could directly attenuate BMP receptor signaling, ${ }^{[135,136]}$ leading to repressed the expression for genes downstream of BMP-mothers against decapentalegic (SMAD) pathway. ${ }^{[136,137]}$ Although we observed CNT-induced repression on hepcidin expression in in vitro cultured HepG2 cells, we could not exclude the possibility of a direct stimulating effect of CNTs on hepcidin expression in the liver in animals. In the current study, we focused on the mechanisms responsible for AI induced by MWCNTs from the perspective of IL-6-hepcidin signaling. Although the other possible mechanisms are not the focus of the current study, more work is needed to elucidate these possibilities. Nonetheless, our data highlighted the crucial role of IL-6-hepcidin signaling in altering systemic iron homeostasis upon MWCNT exposure, and also demonstrated that MWCNTs-PEG and MWCNTs-COOH manifested a weaker capability to trigger this signaling relative to pristine and other functionalized MWCNTs.

To summarize, we uncovered a novel mechanism in understating CNT-conduced indirect toxicity; MWCNT exposure (as the initiating event) triggered a series of key events (including IL-6 induction, hepatic hepcidin stimulation, and sequestered iron for erythroid cells), and these events led to the phenotypes: the development of AI and extramedullary erythropoiesis in spleen (Figure $11 \mathrm{G}$ ). To our best knowledge, this is the first study to report such an adverse secondary effect for CNTs as disordered iron metabolism and AI. We also demonstrated that PEG and $\mathrm{COOH}$ modifications could ameliorate such adverse secondary toxicity. PEG and $\mathrm{COOH}$ modifications, especially for $\mathrm{COOH}$, appeared promising to relieve the key biological process necessary for the development of final phenotypes. Our current findings could be likely used for predictive toxicology of broad nanomaterial types in evaluating pro-inflammatory effects and disturbing effects on iron homeostasis and RBC formation. 


\section{Experimental Section}

Synthesis and Physiochemical Characterization of MWCNTs: Pristine MWCNTs in powder form were purchased from the Cheap Tubes, Inc. (Brattleboro, VT, USA). MWCNT derivatives were prepared from pristine MWCNTs following the instructions, as previously described. ${ }^{[138]}$ Morphology was examined on a TEM (Hitachi, H7500, Japan). Surface charge of MWCNTs, either suspended in Milli-Q water or in culture medium, were measured by a zeta-sizer (Malvern Nano ZS, Nalvem, UK) using a standard method. ${ }^{[139]}$ MWCNT samples were deposited onto silicon wafers, followed by air dry, and were then assessed by confocal micro Raman spectroscopy, as previously reported. ${ }^{[140]}$ TGA analysis was performed on an SDT Q600 thermobalance (TA Instruments, New Castle, USA) under nitrogen gas flow $\left(100 \mathrm{~mL} \mathrm{~min}^{-1}\right)$ at a heating rate of $10{ }^{\circ} \mathrm{C} \mathrm{min}^{-1}$, using alumina crucibles. ${ }^{[141]}$ ICP-MS was performed to determine whether there were significant impurities (e.g., Fe, Al, $\mathrm{Ag}, \mathrm{Cd}, \mathrm{Hg}, \mathrm{Pb}$, and other 19 metals) in these MWCNT samples on an Agilent 7500 instrument (Agilent, Tokyo, Japan), after materials were digested using a microwave on a MARS machine (CEM Corp., Mattews, NC).

To detect PAHs, 16 EPA-PAHs (including acenaphthene, acenaphthylene, fluorene, phenanthrene, anthracene, fluoranthene, pyrene, benzo (a) anthracene, chrysene, benzo (b) fluoranthene, benzo $(k)$ fluoranthene, benzoapyrene, indeno(1,2,3cd)pyrene, dibenz $(a, h)$ anthracene, naphthalene and benzo $(g, h, i)$ perylene) ${ }^{[37,38]}$ were tested using Agilent high-resolution gas chromatography coupled with low-resolution mass spectrometry, as previously described. ${ }^{[142]}$ To determine the endotoxin level, MWCNT samples were subjected to endotoxin test using a Limulus Amebocyte Lysate kit (Pierce, USA).

Cell Culture: Mouse macrophage cell line J774.A1, mouse hepatocarcinoma cell line Hepa1-6, and human hepatocarcinoma cell line HepG2 were purchased from the Shanghai Cell Bank of Type Culture Collection of the Chinese Academy of Sciences. Cells were cultured in Dulbecco's Modified Eagle's Medium or RMPI 1640 (Hyclone), respectively, supplemented with $10 \%$ FBS (Gibco) and $100 \mathrm{U} \mathrm{mL}^{-1}$ penicillin/streptomycin (Gibco) at $37{ }^{\circ} \mathrm{C}$ and with $5 \%$ $\mathrm{CO}_{2}$, as described previously.

Cell Viability Assay: To evaluate cell viability, cells were first seeded at a density of $0.8 \times 10^{4}$ per well in 96-well plates (Corning, Inc., NY, USA) at $37^{\circ} \mathrm{C}$ overnight. Thereafter, cells were treated with MWCNTs at various concentrations. After $24 \mathrm{~h}$ incubation, cell viability was assessed with a Live/Dead viability/cytotoxicity assay kit following the instructions provided by the manufacturer (Invitrogen, Thermo Fisher Scientific, Inc., USA).

qRT-PCR Analysis: Total RNA was extracted from cells using Trizol reagent according to the manufacturer's instruction (Invitrogen, USA). For liver specimens, prior to the RNA extraction, liver samples were first pulverized in liquid nitrogen, and then total RNA was isolated using Trizol. The relative expression levels for genes, including hepcicin, CRP, and IL-6, were determined using SYBR Green qPCR mix (Promega, Inc., USA) on a M×3005P qRT-PCR machine (Bio-Rad, USA). Hypoxanthine phosphoribosyitransferase 1 and glyceraldehyde-3-phosphate dehydrogenase were used as the loading control for normalization for mouse and human genes, respectively. Primers for PCR were provided in Table S1 (Supporting Information).

Animal Experimentation: Male BALB/c mice (seven-week-old and with a body weight of around $25 \mathrm{~g}$ ) were purchased from the
Vital River Laboratories, Beijing, China, and then were housed under the specific pathogen-free and aseptic animal facility. All animal experimental protocols were approved by the Animal Ethics Committee at the Research Center for Eco-Environmental Sciences, Chinese Academy of Sciences. MWCNTs were administrated in $200 \mu \mathrm{L}$ through I.V. and I.P. injection (with only one injection) for $2 \mathrm{~d}$, or were administrated every $3 \mathrm{~d}$ for two weeks through I.P. administration (with a total of four injections during two weeks). It should be noted that no obvious changes in body weight and activities were detected in MWCNT-treated mice over a period of $14 \mathrm{~d}$. When mice were sacrificed, abdominal cavities were washed with cold PBS according to the method, as described in a previous report. ${ }^{[143]}$ The harvested lavages from peritoneal cavities were subjected to total protein assay and cytokine determination by enzyme-linked immune sorbent assay (ELISA), and were also subjected to cell number counting and FACS analysis after RBC lysis with RBC lysis buffer (Solarbio). For the I.T. administration of MWCNTs, anesthetized mice were instilled at the position of the back tongue with MWCNTs in $50 \mu \mathrm{L}$. Meanwhile, a Y-type venous indwelling needle was used as an aid to ensure all materials were injected into the lung. Mice were sacrificed $2 \mathrm{~d}$ post-MWCNT administration, BAL was thereafter harvested for further analyses, similar to the experiments with lavages from abdominal cavities, as described above. All control groups in different exposure settings only received PBS, which was used as vehicle solution for the administration of CNTs.

Blood was collected through heart puncture from left heart atrium. For CBC analysis, $20 \mu \mathrm{L}$ fresh blood was diluted into $2 \mathrm{~mL}$ standard dilution buffer, followed by the analysis on a hematology analyzer (NIHON KOHDEN, MEK-7222K, Japan). Afterward, serum was separated from blood, followed by the determination of cytokines by ELISA. Liver and spleen specimens were collected, and were immediately saved at $-80{ }^{\circ} \mathrm{C}$ for further analyses, or were quickly fixed with $4 \%$ PBS-buffered formaldehyde for histological analysis.

Histological Analysis and Immunohistochemistry Analysis: Tissue specimens were processed for paraffin embedding and sectioning, and H\&E staining was thereafter carried out following the standard protocol. Meanwhile, liver sections were subjected to immunohistochemical staining with an Ab against F4/80 according to the instructions, as previously described. ${ }^{[75]} \mathrm{F} 4 / 80$-positive cells were visualized and counted under a microscope.

Iron Concentration Measurement: Serum iron was determined using a colorimetric assay at $520 \mathrm{~nm}$ using a kit from Nanjing Jiancheng Bioengineering Institute, Nanjing, China. Briefly, $60 \mu \mathrm{L}$ of serum was used to mix with the reduced acid with a ratio of $1: 3$ $(\mathrm{v} / \mathrm{v})$, and then interacted with the dilution containing bispyridine to form a pink complex. The absorption value of the formed pink complex was proportional to the content of iron in serum.

In terms of tissue iron quantification, liver specimens $(100 \mathrm{mg})$ and spleen specimens (50 mg) were first socked in $1 \mathrm{~mL}$ acid solution containing $25 \%(\mathrm{v} / \mathrm{v}) \mathrm{HCl}(36 \%-38 \%)$ and $10 \%(\mathrm{v} / \mathrm{v})$ trichloroacetic acid (guarantee reagent) in $1.5 \mathrm{~mL}$ iron-free tubes. After incubation in water bath at $65{ }^{\circ} \mathrm{C}$ for $3 \mathrm{~d}$, the resulting suspension was added with acid solution to $1.5 \mathrm{~mL}$ iron-free tubes, followed by centrifugation at $12000 \mathrm{~g}$ for $5 \mathrm{~min}$. Chromogen reagent containing $1.65 \mathrm{mmol} \mathrm{\textrm {L } ^ { - 1 }}$ bathophenanthrolinedisulfonic acid disodium salt hydrate (98\%, Sigma-Aldrich) and $1.43 \%(\mathrm{v} / \mathrm{v})$ thioglycolic acid (70\%, Sigma-Aldrich) in high-purity water was 
prepared with protection from light. Afterward, $50 \mu \mathrm{L}$ supernatant was mixed with $50 \mu \mathrm{L}$ acid solution and $1 \mathrm{~mL}$ chromogen reagent mixture (the volume ratio of prepared chromogen reagent, saturated sodium acetate, and high-purity water was 1:5:5). After incubation for $10 \mathrm{~min}$ at room temperature with protection from light, absorbance was measured at $535 \mathrm{~nm}$ on a microplate reader (Varioskan Flash, Thermo, USA).

FACS Analysis of Cell Populations: To identify the subpopulations of recruited cells in abdominal cavities or in BAL, the harvested cells were stained with Abs as follows, FITC-conjugated antimouse CD45 Ab, PerCP-conjugated antimouse CD54 Ab, APC-conjugated antimouse CD11b Ab, PE-conjugated antimouse $\mathrm{F}$ /80 Ab, and PE-conjugated antimouse Gr1 Ab, following the established protocol, as described in the recent report. ${ }^{[29]}$ To count the number of erythroid cells in spleen, the whole spleens were crushed, and all cells were then stained with PE-conjugated antimouse Ter119 Ab, followed by FACS analysis. To recognize macrophages, the total cells from spleen were subjected to RBC lysis with the RBC lysis buffer. Afterward, PE-conjugated antimouse $\mathrm{F}$ //80 Ab was used to count macrophages through FACS. TruStain fcX (antimouse CD16/32) was used to block Fc receptor on cells. FITC-conjugated Rat IgG2b, APC-conjugated Rat IgG2b, PE-conjugated Rat IgG2b, and PerCP-conjugated Rat IgG2b were used as the isotype control, respectively. These Abs were purchased from BioLegend, Inc. (San Diego, USA). FACS analysis was performed on a BD FACSCalibur platform (BD Biosciences) following the standard protocols, as previously described. ${ }^{[75]}$

Cytokine Quantification and Amino-Transaminase Determination: According to the manufacturer's instructions (R\&D systems), $50 \mu \mathrm{L}$ serum, lavage, or culture medium mixed with $50 \mu \mathrm{L}$ of assay dilution was added into plates that were precoated with IL-6 Ab. After $2 \mathrm{~h}$ incubation at room temperature, all plates were washed thoroughly with wash dilution ( $400 \mu \mathrm{L}$ per well) for four times. Thereafter, $100 \mu \mathrm{L}$ IL-6 conjugate solution was added into each plate. After $2 \mathrm{~h}$ incubation at room temperature, all plates were washed thoroughly with wash dilution for four times again. Finally, the absorption value of horseradish peroxidase labeled IL-6 was recorded at $450 \mathrm{~nm}$ on a microplate reader (Varioskan Flash, Thermo, USA). The quantification of TNF- $\alpha$ was similar to that for IL-6 using a kit from R\&D systems. The concentrations of cytokines were calculated according to the standard curves made by the standard solutions.

Serum ALT and AST levels were individually assayed with detection kits following the standard protocols from the manufacturer (Q\&D Systems, Shanghai Qiao Du Biotechnology, Co., Ltd.).

Statistical Analysis: The SPSS Statistics package was used to analyze the experimental data. Independent $t$-test and one-way analysis of variance (ANOVA) test were applied to analyze experimental data. Data were shown in mean \pm standard error of the mean (SEM). Statistical significance was determined with $P$ value less than 0.05 .

\section{Supporting Information}

Supporting Information is available from the Wiley Online Library or from the author.

\section{Acknowledgements}

This work was supported by a grant under the national "973" program (Grant No. 2014CB932000), the Strategic Priority Research Program of the Chinese Academy of Sciences (Grant No. XDB14000000), and grants from the National Natural Science Foundation of China (Grant Nos. 21425731, 21377159, 91543124, and 81373039). The authors thank the laboratory members for reagents and assistance with experiments. There is no potential conflict of interests to disclose.

[1] R. H. Baughman, Science 2002, 297, 787.

[2] R. Li, R. A. Wu, L. Zhao, M. Wu, L. Yang, H. Zou, ACS Nano 2010, 4, 1399.

[3] S. Beg, M. Rizwan, A. M. Sheikh, M. S. Hasnain, K. Anwer, K. Kohli, J. Pharm. Pharmacol. 2011, 63, 141.

[4] V. Rastogi, P. Yadav, S. S. Bhattacharya, A. K. Mishra, N. Verma, A. Verma, J. K. Pandit, J. Drug Delivery 2014, 2014, 670815.

[5] S. Vardharajula, S. Z. Ali, P. M. Tiwari, E. Eroglu, K. Vig, V. A. Dennis, S. R. Singh, Int. J. Nanomed. 2012, 7, 5361.

[6] H. J. Johnston, G. R. Hutchison, F. M. Christensen, S. Peters, S. Hankin, K. Aschberger, V. Stone, Nanotoxicology 2010, 4, 207.

[7] Y. Bai, Y. Zhang, J. Zhang, Q. Mu, W. Zhang, E. R. Butch, S. E. Snyder, B. Yan, Nat. Nanotechnol. 2010, 5, 683.

[8] J. P. Ryman-Rasmussen, M. F. Cesta, A. R. Brody, J. K. Shipley-Phillips, J. I. Everitt, E. W. Tewksbury, O. R. Moss, B. A. Wong, D. E. Dodd, M. E. Andersen, J. C. Bonner, Nat. Nanotechnol. 2009, 4, 747.

[9] Y. Yu, Q. Zhang, Q. Mu, B. Zhang, B. Yan, Nanoscale Res. Lett. 2008, 3, 271.

[10] D. Elgrabli, M. Floriani, S. Abella-Gallart, L. Meunier, C. Gamez, P. Delalain, F. Rogerieux, J. Boczkowski, G. Lacroix, Part. Fibre Toxicol. 2008, 5, 20.

[11] C. Qu, L. Wang, J. He, J. Tan, W. Liu, S. Zhang, C. Zhang, Z. Wang, S. Jiao, S. Liu, G. Jiang, Gene 2012, 493, 9.

[12] Y. Chen, Z. Wang, M. Xu, X. Wang, R. Liu, Q. Liu, Z. Zhang, T. Xia, J. Zhao, G. Jiang, Y. Xu, S. Liu, ACS Nano 2014, 8, 5813.

[13] R. Chen, L. Zhang, C. Ge, M. T. Tseng, R. Bai, Y. Qu, C. Beer, H. Autrup, C. Chen, Chem. Res. Toxicol. 2015, 28, 440.

[14] R. R. Mercer, J. F. Scabilloni, A. F. Hubbs, L. Wang, L. A. Battelli, W. McKinney, V. Castranova, D. W. Porter, Part. Fibre Toxicol. 2013, 10, 38.

[15] P. Jackson, K. S. Hougaard, U. Vogel, D. Wu, L. Casavant, A. Williams, M. Wade, C. L. Yauk, H. Wallin, S. Halappanavar, Mutat. Res. 2012, 745, 73.

[16] P. Jackson, K. S. Hougaard, A. M. Boisen, N. R. Jacobsen, K. A. Jensen, P. Moller, G. Brunborg, K. B. Gutzkow, O. Andersen, S. Loft, U. Vogel, H. Wallin, Nanotoxicology 2012, 6, 486.

[17] B. Gao, H. Wang, F. Lafdil, D. Feng, J. Hepatol. 2012, 57, 430.

[18] Z. Zhou, M. J. Xu, B. Gao, Cell Mol. Immunol. 2015, 13, 301.

[19] A. E. Armitage, L. A. Eddowes, U. Gileadi, S. Cole, N. Spottiswoode, T. A. Selvakumar, L. P. Ho, A. R. M. Townsend, H. Drakesmith, Blood 2011, 118, 4129.

[20] B. Gao, W.-I. Jeong, Z. Tian, Hepatology 2007, 47, 729.

[21] H. Drakesmith, E. Nemeth, T. Ganz, Cell Metab. 2015, 22, 777.

[22] T. Ganz, E. Nemeth, Hematology Am. Soc. Hematol. Educ. Program 2011, 2011, 538.

[23] K. Ganeshaguru, A. V. Hoffbrand, R. W. Grady, A. Cerami, Biochem. Pharmacol. 1980, 29, 1275.

[24] J. A. Duce, A. Tsatsanis, M. A. Cater, S. A. James, E. Robb, K. Wikhe, S. L. Leong, K. Perez, T. Johanssen, M. A. Greenough, H. H. Cho, D. Galatis, R. D. Moir, C. L. Masters, C. McLean, 
R. E. Tanzi, R. Cappai, K. J. Barnham, G. D. Ciccotosto, J. T. Rogers, A. I. Bush, Cell 2010, 142, 857.

[25] R. L. Jurado, Clin. Infect. Dis. 1997, 25, 888.

[26] N. C. Andrews, P. J. Schmidt, Ann. Rev. Physiol. 2007, 69, 69.

[27] T. Ganz, Physiol. Rev. 2013, 93, 1721.

[28] K. Michels, E. Nemeth, T. Ganz, B. Mehrad, PLoS Pathogens 2015, 11, e1004998.

[29] J. Ma, R. Li, G. Qu, H. Liu, B. Yan, T. Xia, Y. Liu, S. Liu, Nanoscale 2016, 8, 18070.

[30] S. Tenzer, D. Docter, J. Kuharev, A. Musyanovych, V. Fetz, R. Hecht, F. Schlenk, D. Fischer, K. Kiouptsi, C. Reinhardt, K. Landfester, H. Schild, M. Maskos, S. K. Knauer, R. H. Stauber, Nat. Nanotechnol. 2013, 8, 772.

[31] Z. Zhao, M. Espanol, J. Guillem-Marti, D. Kempf, A. Diez-Escudero, M. P. Ginebra, Nanoscale 2016, 8, 1595.

[32] C. Gao, H. He, L. Zhou, X. Zheng, Y. Zhang, Chem. Mater. 2009, $21,360$.

[33] X. Jiang, P. J. Schoenmakers, J. L. J. van Dongen, X. Lou, V. Lima, J. Brokken-Zijp, Anal. Chem. 2003, 75, 5517.

[34] J. Ado, G. C. Luiz, Phys. Chem. Chem. Phys 2012, 14, 15246.

[35] A. C. Ferrari, Solid State Commun. 2007, 143, 47.

[36] A. Sadezky, H. Muckenhuber, H. Grothe, R. Niessner, U. Pöschl, Carbon 2005, 43, 1731.

[37] J. T. Andersson, C. Achten, Polycyclic Aromat. Compd. 2015, 35, 330.

[38] Z. Zelinkova, T. Wenzl, Polycyclic Aromat. Compd. 2015, 35, 248.

[39] A. K. Haritash, C. P. Kaushik, J. Hazard. Mater. 2009, 169, 1.

[40] C. Genies, A. Jullien, E. Lefebvre, M. Revol, A. Maitre, T. Douki, Toxicol. in Vitro 2016, 35, 1.

[41] D. Bohrer, R. Hörner, P. C. do Nascimento, M. Adaime, M. E. Pereira, A. F. Martins, S. A. Hartz, J. Pharm. Biomed. Anal. 2001, 26, 811.

[42] G. Qu, S. Liu, S. Zhang, L. Wang, X. Wang, B. Sun, N. Yin, X. Gao, T. Xia, J.-J. Chen, G.-B. Jiang, ACS Nano 2013, 7, 5732.

[43] S. Luanpitpong, L. Wang, Y. Rojanasakul, Nanomedicine 2014, 9, 895.

[44] K. Donaldson, F. A. Murphy, R. Duffin, C. A. Poland, Part. Fibre Toxicol. 2010, 7, 5.

[45] L. Rushton, Rev. Environ. Health 2007, 22, 195.

[46] R. Li, X. Wang, Z. Ji, B. Sun, H. Zhang, C. H. Chang, S. Lin, H. Men, Y.-P. Liao, M. Wang, Z. Li, A. A. Hwang, T.-B. Song, R. Xu, Y. Yang, J. I. Zink, A. E. Nel, T. Xia, ACS Nano 2013, 7, 2352.

[47] V. Castranova, P. A. Schulte, R. D. Zumwalde, Acc. Chem. Res. 2013, 46, 642 .

[48] E. D. Kuempel, V. Castranova, C. L. Geraci, P. A. Schulte, J. Nanopart. Res. 2012, 14, 1029.

[49] X. Wang, T. Xia, M. C. Duch, Z. Ji, H. Zhang, R. Li, B. Sun, S. Lin, H. Meng, Y.-P. Liao, M. Wang, T.-B. Song, Y. Yang, M. C. Hersam, A. E. Nel, Nano Lett. 2012, 12, 3050.

[50] K. C. Stone, R. R. Mercer, P. Gehr, B. Stockstill, J. D. Crapo, Am. J. Respir. Cell Mol. Biol. 1992, 6, 235.

[51] I. Guseva Canu, T. F. Bateson, V. Bouvard, M. Debia, C. Dion, K. Savolainen, I. J. Yu, Int. J. Hyg. Environ. Health 2016, 219, 166.

[52] D. W. Porter, A. F. Hubbs, R. R. Mercer, N. Wu, M. G. Wolfarth, K. Sriram, S. Leonard, L. Battelli, D. Schwegler-Berry, S. Friend, Toxicology 2010, 269, 136.

[53] J. H. Han, E. J. Lee, J. H. Lee, K. P. So, Y. H. Lee, G. N. Bae, S.-B. Lee, J. H. Ji, M. H. Cho, I. J. Yu, Inhalation Toxicol. 2008, 20, 741.

[54] J. Ma, R. Liu, X. Wang, Q. Liu, Y. Chen, R. P. Valle, Y. Y. Zuo, T. Xia, S. Liu, ACS Nano 2015, 9, 10498.

[55] M. Mihara, M. Hashizume, H. Yoshida, M. Suzuki, M. Shiina, Clin. Sci. 2012, 122, 143.

[56] M. A. Dobrovolskaia, S. E. McNeil, Nat. Nanotechnol. 2007, 2, 469.

[57] T. Chavakis, Eur. J. Clin. Invest. 2012, 42, 686.
[58] N. Borregaard, Immunity 2010, 33, 657.

[59] W. J. Sandberg, M. Lag, J. A. Holme, B. Friede, M. Gualtieri, M. Kruszewski, P. E. Schwarze, T. Skuland, M. Refsnes, Part. Fibre Toxicol. 2012, 9, 32.

[60] C. Shi, E. G. Pamer, Nat. Rev. Immunol. 2011, 11, 762.

[61] E. Kolaczkowska, P. Kubes, Nat. Rev. Immunol. 2013, 13, 159.

[62] D. Vestweber, Nat. Rev. Immunol. 2015, 15, 692.

[63] A. C. Thomas, A. Wynn, J. W. Pollard, Nature 2013, 496, 445.

[64] F. Tacke, H. W. Zimmermann, J. Hepatol. 2014, 60, 1090.

[65] A. Seifalian, Int. J. Nanomed. 2011, 6, 2963.

[66] R. Singh, D. Pantarotto, L. Lacerda, G. Pastorin, C. Klumpp, M. Prato, A. Bianco, K. Kostarelos, Proc. Natl. Acad. Sci. USA 2006, 103, 3357.

[67] J. T. W. Wang, N. Rubio, H. Kafa, E. Venturelli, C. Fabbro, C. Ménard-Moyon, T. Da Ros, J. K. Sosabowski, A. D. Lawson, M. K. Robinson, M. Prato, A. Bianco, F. Festy, J. E. Preston, K. Kostarelos, K. T. Al-Jamal, J. Controlled Release 2016, 224, 22.

[68] J. Liu, B. Sun, H. Yin, S. Liu, Medicine 2016, 95, e3150.

[69] M. W. Hentze, M. U. Muckenthaler, N. C. Andrews, Cell 2004, $117,285$.

[70] Y. L. Wu, R. M. Brosh, Nucleic Acids Res. 2012, 40, 4247.

[71] K. Brzoska, S. Meczynska, M. Kruszewski, Acta Biochim. Pol. 2006, 53, 685 .

[72] T. Ganz, E. Nemeth, Annu. Rev. Med. 2011, 62, 347.

[73] T. Ganz, E. Nemeth, Biochim. Biophys. Acta 2012, 1823, 1434.

[74] T. Ganz, J. Innate Immun. 2012, 4, 446.

[75] S. Liu, R. N. V. S. Suragani, F. Wang, A. Han, W. Zhao, N. C. Andrews, J.-J. Chen, J. Clin. Invest.. 2007, 117, 3296.

[76] R. Origa, R. Galanello, T. Ganz, N. Giagu, L. Maccioni, G. Faa, E. Nemeth, Haematologica 2007, 92, 583.

[77] W. Liu, Y. Hou, H. Chen, H. Wei, W. Lin, J. Li, M. Zhang, F. He, Y. Jiang, Proteomics 2011, 11, 3556.

[78] T. Ganz, E. Nemeth, Nat. Rev. Immunol. 2015, 15, 500.

[79] L. Kautz, G. Jung, E. V. Valore, S. Rivella, E. Nemeth, T. Ganz, Nat. Genet. 2014, 46, 678.

[80] L. Ruibin, W. Ren'an, Z. Liang, Q. Hongqiang, W. Jianlin, Z. Jingwen, B. Ruyi, Z. Hanfa, Nanotechnology 2014, 25, 495102.

[81] T. M. Sager, M. W. Wolfarth, M. Andrew, A. Hubbs, S. Friend, T. H. Chen, D. W. Porter, N. Wu, F. Yang, R. F. Hamilton, A. Holian, Nanotoxicology 2014, 8, 317.

[82] S. Hosseini, F. Ibrahim, I. Djordjevic, L. H. Koole, Analyst 2014 $139,2933$.

[83] R. Evstatiev, C. Gasche, Gut 2012, 61, 933.

[84] J. Kaplan, D. M. Ward, I. De Domenico, Int. J. Hematol. 2011, 93, 14.

[85] E. Nemeth, T. Ganz, Hematol. Oncol. Clin. North Am. 2014, 28, 671.

[86] B. J. McCranor, J. M. Langdon, O. D. Prince, L. K. Femnou, A. E. Berger, C. Cheadle, C. I. Civin, A. Kim, S. Rivera, T. Ganz, S. Vaulont, Q.-L. Xue, J. D. Walston, C. N. Roy, Haematologica 2013, 98, 1633.

[87] G. Weiss, Biochim. Biophys. Acta 2009, 1790, 682.

[88] G. Weiss, L. T. Goodnough, New Eng. J. Med. 2005, 352, 1011.

[89] A. Kim, E. Fung, S. G. Parikh, E. V. Valore, V. Gabayan, E. Nemeth, T. Ganz, Blood 2014, 123, 1129.

[90] A. Kim, E. Fung, S. G. Parikh, V. Gabayan, E. Nemeth, T. Ganz, Blood Cells, Mol., Dis. 2016, 56, 31.

[91] T. Ganz, E. Nemeth, Cold Spring Harb Perspect. Med. 2012, 2, a011668.

[92] G. Tarantino, S. Savastano, D. Capone, A. Colao, World J. Gastroenterol. 2011, 17, 3776.

[93] Y. Sadahira, M. Mori, Pathol. Int. 1999, 49, 841.

[94] P. Ramos, C. Casu, S. Gardenghi, L. Breda, B. J. Crielaard, E. Guy, M. F. Marongiu, R. Gupta, R. L. Levine, O. Abdel-Wahab, B. L. Ebert, N. Van Rooijen, S. Ghaffari, R. W. Grady, P. J. Giardina, S. Rivella, Nat. Med. 2013, 19, 437. 
[95] S. Sarvothaman, R. B. Undi, S. R. Pasupuleti, U. Gutti, R. K. Gutti, Blood Res. 2015, 50, 73.

[96] S. Liu, S. Bhattacharya, A. Han, R. N. Suragani, W. Zhao, R. C. Fry, J. J. Chen, Br. J. Haematol. 2008, 143, 129.

[97] K. I. T. Kina, E. I. J. I. Takayama, K. Wada, A. S. Majumdar, Br. J. Haematol. 2000, 109, 280.

[98] Y. N. Zhang, W. Poon, A. J. Tavares, I. D. McGilvray, W. C. Chan, J. Controlled Release 2016, 240, 332.

[99] E. Blanco, H. Shen, M. Ferrari, Nat. Biotechnol. 2015, 33, 941.

[100] A. Nel, T. Xia, L. Madler, N. Li, Science 2006, 311, 622.

[101] L. G. Delogu, G. Vidili, E. Venturelli, C. Ménard-Moyon, M. A. Zoroddu, G. Pilo, P. Nicolussi, C. Ligios, D. Bedognetti, F. Sgarrella, R. Manetti, A. Bianco, Proc. Natl. Acad. Sci. USA 2012, 109, 16612.

[102] A. Albini, A. Pagani, L. Pulze, A. Bruno, E. Principi, T. Congiu, E. Gini, A. Grimaldi, B. Bassani, S. De Flora, M. de Eguileor, D. M. Noonan, Int. J. Nanomed. 2015, 10, 6133.

[103] A. Al Faraj, K. Cieslar, G. Lacroix, S. Gaillard, E. Canet-Soulas, Y. Crémillieux, Nano Lett. 2009, 9, 1023.

[104] M. Botros, K. A. Sikaris, Clin. Biochem. Rev. (Ultimo, Aust.) 2013, 34, 117.

[105] H. Nyblom, U. Berggren, J. Balldin, R. Olsson, Alcohol Alcohol. 2004, 39, 336.

[106] E. Liaskou, D. V. Wilson, Y. H. Oo, Mediators Inflammation 2012, 2012, 1.

[107] R. Kapur, K. M. J. Heitink-Poll, L. Porcelijn, A. E. H. Bentlage, M. C. A. Bruin, R. Visser, D. Roos, R. B. M. Schasfoort, M. de Haas, C. E. van der Schoot, G. Vidarsson, Blood 2015, 125, 1793.

[108] J. A. Chasis, N. Mohandas3, Blood 2008, 112, 470.

[109] C. R. Walkley, Int. J. Hematol. 2011, 93, 10.

[110] S. Nagata, Immunol. Rev. 2007, 220, 237.

[111] L. Rushton, Rev. Environ. Health 2007, 22, 255.

[112] G. Ravasi, S. Pelucchi, P. Trombini, R. Mariani, N. Tomosugi, G. L. Modignani, M. Pozzi, E. Nemeth, T. Ganz, H. Hayashi, D. Barisani, A. Piperno, PLoS One 2012, 7, e36425.

[113] Y. Kanamori, M. Murakami, T. Matsui, M. Funaba, Gene 2014 $551,119$.

[114] S. Lee, D. Khang, S.-H. Kim, Int. J. Nanomed. 2015, 10, 2697.

[115] Z. Liu, Y. Liu, D. Peng, J. Biomed. Mater. Res. A 2015, 103 , 2770.

[116] B. Li, X.-Y. Zhang, J.-Z. Yang, Y.-J. Zhang, W.-X. Li, C.-H. Fan, Q. Huang, Int. J. Nanomed. 2014, 9, 4697.

[117] X. Tan, L. Feng, J. Zhang, K. Yang, S. Zhang, Z. Liu, R. Peng, ACS Appl. Mater. Interfaces 2013, 5, 1370.

[118] P. Aggarwal, J. B. Hall, C. B. McLeland, M. A. Dobrovolskaia, S. E. McNeil, Adv. Drug Delivery Rev. 2009, 61, 428.

[119] B. Glomstad, D. Altin, L. Sorensen, J. Liu, B. M. Jenssen, A. M. Booth, Environ. Sci. Technol. 2016, 50, 2660.

[120] S. Kontos, J. A. Hubbell, Chem. Soc. Rev. 2012, 41, 2686.
[121] Z. Liu, X. Dong, L. Song, H. Zhang, L. Liu, D. Zhu, C. Song, X. Leng, J. Biomed. Mater. Res., Part A 2014, 102, 665.

[122] C.-Y. Tseng, J.-S. Wang, M.-W. Chao, Cardiovasc. Toxicol. 2016, 1.

[123] L. C. Simon, C. M. Sabliov, Drug Metab. Rev. 2014, 46, 128.

[124] J. P. M. Almeida, A. L. Chen, A. Foster, R. Drezek, Nanomedicine 2011, 6, 815

[125] B. J. Sasu, K. S. Cooke, T. L. Arvedson, C. Plewa, A. R. Ellison, J. Sheng, A. Winters, T. Juan, H. Li, C. G. Begley, G. Molineux, Blood 2010, 115, 3616.

[126] E. Nemeth, S. Rivera, V. Gabayan, C. Keller, S. Taudorf, B. K. Pedersen, T. Ganz, J. Clin. Invest. 2004, 113, 1271.

[127] T. Ganz, Physiol. Rev. 2013, 93, 1721.

[128] D. J. R. Lane, A. M. Merlot, M. L. H. Huang, D. H. Bae, P. J. Jansson, S. Sahni, D. S. Kalinowski, D. R. Richardson, Biochim. Biophys. Acta, Mol. Cell Res. 2015, 1853, 1130.

[129] D. Finazzi, P. Arosio, Arch. Toxicol. 2014, 88, 1787.

[130] E. C. Theil, Inorg. Chem. 2013, 52, 12223.

[131] C. Casu, P. R. Oikonomidou, H. Chen, V. Nandi, Y. Ginzburg, P. Prasad, R. E. Fleming, Y. M. Shah, E. V. Valore, E. Nemeth, T. Ganz, B. MacDonald, S. Rivella, Blood 2016, 128, 265.

[132] N. L. Parrow, R. E. Fleming, Annu. Rev. Nutr. 2014, 34, 77.

[133] E. Ramos, L. Kautz, R. Rodriguez, M. Hansen, V. Gabayan, Y. Ginzburg, M.-P. Roth, E. Nemeth, T. Ganz, Hepatology (Baltimore, MD) 2011, 53, 1333.

[134] N. Gao, Q. Zhang, Q. Mu, Y. Bai, L. Li, H. Zhou, E. R. Butch, T. B. Powell, S. E. Snyder, G. Jiang, B. Yan, ACS Nano 2011, 5, 4581.

[135] L. Hou, X. Zhang, D. Wang, A. Baccarelli, Int. J. Epidemiol. 2012, $41,79$.

[136] B. Andriopoulos Jr., E. Corradini, Y. Xia, S. A. Faasse, S. Chen, L. Grgurevic, M. D. Knutson, A. Pietrangelo, S. Vukicevic, H. Y. Lin, J. L. Babitt, Nat. Genet. 2009, 41, 482.

[137] N. Zhao, A.-S. Zhang, C. A. Enns, J. Clin. Invest. 2013, 123, 2337.

[138] L. Wu, Y. Zhang, C. Zhang, X. Cui, S. Zhai, Y. Liu, C. Li, H. Zhu, G. Qu, G. Jiang, B. Yan, ACS Nano 2014, 8, 2087.

[139] X. Wang, T. Xia, S. A. Ntim, Z. Ji, S. George, H. Meng, H. Zhang, V. Castranova, S. Mitra, A. E. Nel, ACS Nano 2010, 4, 7241.

[140] L. Rui, L. Jingfu, Z. Xiaoxia, S. Mengtao, J. Guibin, Anal. Chem. 2011, 83, 9131.

[141] M. Xu, J. Zhu, F. Wang, Y. Xiong, Y. Wu, Q. Wang, J. Weng, Z. Zhang, W. Chen, S. Liu, ACS Nano 2016, 10, 3267.

[142] Q. X. Lv, W. Wang, X. H. Li, L. Yu, Y. Zhang, Y. Tian, Environ. Pollut. 2015, 199, 219.

[143] P. Craig, A. D. Rodger, K. Ian, M. Andrew, W. William, A. H. S. Anthony, S. Vicki, B. Simon, M. William, D. Ken, Nat. Nanotechnol. 2008, 3, 423.

Received: November 16, 2016 Revised: December 26, 2016 Published online: February 13, 2017 